\title{
A New Composite Biomaterial Made from Sunflower Proteins, Urea, and Soluble Polymers Obtained from Industrial and Municipal Biowastes to Perform as Slow Release Fertiliser
}

\author{
Philippe Evon ${ }^{1, *} \mathbb{0}$, Laurent Labonne ${ }^{1}$, Elio Padoan ${ }^{2}{ }^{-}$, Carlos Vaca-Garcia ${ }^{1}$, Enzo Montoneri ${ }^{2, *}$, Valter Boero ${ }^{2}$ \\ and Michéle Negre ${ }^{2}$ \\ 1 INP, Laboratoire de Chimie Agro-Industrielle, Université de Toulouse, ENSIACET, 4 Allée Emile Monso, \\ BP 44362, 31030 Toulouse, France; Laurent.Labonne@ensiacet.fr (L.L.); carlos.vacagarcia@ensiacet.fr (C.V.-G.) \\ 2 Dipartimento di Scienze Agrarie, Università di Torino, Forestali e Alimentari, Largo P. Braccini 2, \\ 10095 Grugliasco, Italy; elio.padoan@unito.it (E.P.); valter.boero@unito.it (V.B.); michele.negre@unito.it (M.N.) \\ * Correspondence: philippe.evon@ensiacet.fr (P.E.); enzo.montoneri@gmail.com (E.M.)
}

Citation: Evon, P.; Labonne, L.; Padoan, E.; Vaca-Garcia, C.; Montoneri, E.; Boero, V.; Negre, M. A New Composite Biomaterial Made from Sunflower Proteins, Urea, and Soluble Polymers Obtained from Industrial and Municipal Biowastes to Perform as Slow Release Fertiliser. Coatings 2021, 11, 43. https://doi.org/ 10.3390/coatings11010043

Received: 17 December 2020 Accepted: 30 December 2020 Published: 2 January 2021

Publisher's Note: MDPI stays neutral with regard to jurisdictional clai$\mathrm{ms}$ in published maps and institutional affiliations.

Copyright: (C) 2021 by the authors. Licensee MDPI, Basel, Switzerland. This article is an open access article distributed under the terms and conditions of the Creative Commons Attribution (CC BY) license (https:// creativecommons.org/licenses/by/ $4.0 /)$.

\begin{abstract}
Controlled-release fertilizers (CRF) are needed under current agriculture practice to decrease the environmental impact caused by fertilizer doses applied in excess of plants' uptake rate. Commercial CRF are available. They are manufactured from mineral fertilizers encapsulated into a synthetic polymer matrix or coated by a polymer layer. However, substitution of fossil sourced organic polymers with biopolymers is a major environmental concern. In the present paper, we describe the manufacture by a continuous twin-screw extrusion process, and the mechanical and chemical properties of injection-molded composite pellets containing $90 \%$ sunflower protein concentrate (SPC) matrix, and $5-10 \%$ of a biopolymer (BP) obtained from municipal biowastes (MBW), and/or urea (U). The reported results show that SPC-BP-U behaves as an efficient eco-friendly CRF. BP contributes to several benefits to the performance of the composite pellets, upon increasing surface hardness, and controlling the formation of ammonia from urea hydrolysis and the release of organic nitrogen. The SPC-BP-U appears a powerful eco-friendly CRF to supply organic C and the three major N, P, and $\mathrm{K}$ nutrients to soil and plants. It offers worthwhile scope for being tested in the cultivation of specific plants under the real operational conditions of agriculture practices.
\end{abstract}

Keywords: biopolymers; sunflower protein concentrate; municipal bio-waste; urea; slowrelease fertilizers

\section{Introduction}

The fertilizer industry faces a continuing challenge to improve its products and increase the efficiency of their use, particularly of nitrogenous fertilizers, and to minimize any possible adverse environmental impact. This is done either through improvement of fertilizers already in use, or through development of new specific fertilizer types [1]. One specific objective in Europe is the development of new sustainable fertilizers with the aim of reducing the consumption and/or import of conventional mineral fertilizers from third-world countries, and of $\mathrm{N}$ fertilizers based on energy-intensive production process. The development of innovative controlled-released fertilizers (CRFs) could limit the consumption of the traditional ones. Indeed, CRFs present the interest to better match the plants' need for nutrients over time.

Several CRFs products are already available in the market. They are manufactured from blends of fertilizers as active principle and organic polymers. There are two major CRFs types [2]. In the first, the fertilizer is encapsulated into the polymer matrix. In the second, the fertilizer is coated by a polymer layer. The fertilizer bioavailability for the plant uptake is controlled by the diffusion rate through the pores of the polymer matrix or through the surrounding polymer shell. Although several commercial CRFs can achieve 
satisfactory fertilizers release rate, the plastic polymer in the blend raises concern for its low biodegradability and the accumulation of plastic impurities in soil. The new EU regulation on fertilizing products addresses the degradability of the organic matter of CRFs by stipulating $90 \%$ conversion of the organic carbon into $\mathrm{CO}_{2}$ in a maximum of 24 months. The specific challenge focuses on finding organic polymers that comply with the biodegradability EU requirements, while achieving the controlled release of nutrients in the best possible manner.

Much research work has been carried out to develop new CRFs containing natural polymers, instead of synthetic polymers. The substitution of synthetic polymers derived from fossil sources with natural polymers is a current major environmental issue [3]. Although biodegradable polymers can be also synthesized from monomers obtained from the petrochemical industry, the consumption of chemicals from fossil sources is a major source of GHG emission. In addition, it contributes to the depletion of fossil sources. Natural polymers such as lignin, starch, chitin, cellulose, and other polysaccharides (e.g., $k$-carrageenan) have been investigated to make CRFs. Generally, these cannot be used in natural pure form as effective coating material due to their inherent properties, such as poor mechanical properties, hydrophobicity, high industrial demand, poor solubility, and processability. These imply limitations for their use.

To overcome the above criticalities, researchers have focused their work on chemical and physical modifications of natural polymers. Biopolymers from monomers obtained from renewable source have also been obtained, e.g., polylactic acid (PLA) or poly hydroxyl alkanoates (PHA). Aims of current research on CRFs are to reduce production cost, improve nutrient release rate, optimize organic matter biodegradability rate, and guarantee crushing strength to bear crack resistance under environmental stresses. These three properties need to be compatible with each other. Indeed, a poor mechanical strength or high biodegradability may result in faster nutrient release rate, excess nutrient availability over the plant uptake rate, high nutrient leaching from soil into ground, and low CRFs efficiency. High crushing strength also facilitates the handling and transportation and reduces the water absorption [4].

In the present work, the current CRFs issues have been addressed by fabricating a new material out of three components. These are a sunflower protein concentrate (SPC) obtained from sunflower oil cake (SOC), a biopolymer (BP) obtained from municipal biowaste (MBW), and commercial urea (U). All three components contain N. Three different blends were manufactured, i.e., SPC- $10 \%$ U, SPC- $10 \%$ BP, SPC- $5 \%$ U- $5 \%$ BP. The underlying rationale of the work was to use SPC as polymer matrix, and BP and $U$ as fillers/active principles. The reason for this approach is based on the following literature data reported for SPC, BP and U.

The SPC is well known biopolymer used in human nutrition for its nutritional value [5], and potential antioxidant properties and benefits for disease prevention and aging retardation [6]. SPC are reported also to have also good processability to manufacture films by solvent casting [7] and extrusion at $160{ }^{\circ} \mathrm{C}$ [8]. This material therefore seemed a potential eco-friendly matrix to be used for manufacturing new CRFs.

The BP is obtained by chemical hydrolysis of fermented unsorted urban food wastes. The BPs sourcing food wastes contain all major animal and vegetable natural polymers. Upon anaerobic fermentation, the most readily degradable fats, polysaccharides, and proteins are converted to methane and carbon dioxide. The solid anaerobic digestate (AD) contains the recalcitrant lignocellulosic fraction. The BP, obtained from AD chemical hydrolysis, contains a mix of water-soluble molecules with molecular weight from 5 to above $750 \mathrm{kDa}$ [9]. These molecules are water soluble lignocellulosic fragments. They keep the memory of the macromolecularity and functional groups, and of the mechanical properties of the proximates in the parent food wastes. However, BP is water soluble and thermally stable up to $200{ }^{\circ} \mathrm{C}$. This allows for fabricating, by solvent casting and melt extrusion, composite articles containing BP in blends with synthetic polymers such as polyethyleneco-vinyl alcohol [10] and polyethylene-co-acrylic acid [11]. The blends have been proven 
to have higher mechanical resistance, compared to the article manufactured from the neat synthetic polymer only. The BP is not biodegradable. However, based on its sourcing material, no adverse effect is expected from its accumulation in soil. Indeed, MBW anaerobic digestates and/or compost are used as soil amending agents and/or fertilizers. The BP has also been proven [9] more efficient soil fertilizer and plant growth biostimulant in the cultivation of several food and ornamental plants, in comparison with its sourcing fermented MBW materials and with commercial organo-inorganic peat and leonardite derived products claimed by the vendor as plant biostimulants. This material seemed therefore a potential processable filler, capable of increasing the mechanical resistance of the SPC matrix and to perform at the same time as active fertilizer principle in CRFs.

Urea is a main commercial fertilizer. Its world consumption amounts to approximately $51 \mathrm{Mt} / \mathrm{yr}$ [12]. In the present work, urea has been chosen as reference commercial $\mathrm{N}$ fertilizer. Urea and lignin materials have also been investigated for use in the CRF field. Urea coated with pine lignin [13] mixed with various types of additives exhibited 59\% higher crushing strength than the uncoated fertilizer. Urea coated with four types of lignin, recovered from the effluent liquor of the paper and paper industry [14], gave products with film forming properties, but unsatisfactory release rate. The same occurred for urea granules fabricated by mixing urea with kraft lignin under melting conditions [15]. Kraft lignin was added to a tapioca starch-urea-borate matrix to modulate the starch matrix hydrophilicity properties and reduce the urea release in water [16]. The final film product remained intact after one month of contact time with water. The retardation of the urea release rate by Kraft lignin was confirmed also for other formulations [15]. Based on these results, the BP keeping the memory of the pristine lignin matter present in the sourcing food waste seemed to the authors of the present work to offer intriguing perspectives for use together with urea and the SPC matrix in the manufacture of new CRFs.

The main aims of the present work were to develop a twin-screw extrusion process tailored to the fabrication of the new SPC-BP-U pellets and to test the pellets mechanical behavior and release rate in solution of organic and inorganic nitrogen. The principal conclusions of the work are that the developed twin-screw extrusion process successfully produces the SPC-BP-U pellets and that the pellets behave as CRFs. The results also suggest that $\mathrm{BP}$ has positive effects on the mechanical properties of the pellets and on the chemical behavior of the organic and inorganic $\mathrm{N}$ species released in solution.

\section{Materials and Methods}

\section{1. $S P C, B P, U$, and Other Reagents}

The BP was available from previous work [9]. It was obtained from the anaerobic digestate of the MBW processed in the ACEA waste treatment plant in Pinerolo, Italy. The sampled digestate was hydrolyzed at $60^{\circ} \mathrm{C}$ in $\mathrm{pH} 13$ water. The liquid hydrolysate was separated from the insoluble residue by centrifugation and then filtered through polysulphone membrane with $5 \mathrm{kDa}$ cut off. The membrane retentate was dried at $60{ }^{\circ} \mathrm{C}$ to yield the solid BP.

The SPC was obtained from a sunflower oil cake (SOC). To obtain it, SOC was sieved using a Ritec (France) 600 vibrating sieve shaker fitted with a $1 \mathrm{~mm}$ grid. The oversize was mainly composed of solid particles from the seed hull, and therefore rich in fibers. Conversely, the undersize (SPC) was enriched with the smaller particles coming from the kernel of the seed, thus having a high protein content. This resulted in a higher content of SPC in proteins, the latter having been evaluated at $50.7 \% \pm 0.1 \%$ (in proportion to the SPC dry weight) using the Kjeldahl method [17]. The other chemicals inside SPC were minerals, lipids, cellulose, hemicelluloses, lignins, and water-solubles, with contents of $8.6 \% \pm 0.1 \%, 1.4 \% \pm 0.1 \%, 11.0 \% \pm 0.9 \%, 11.2 \% \pm 1.7 \%, 0.8 \% \pm 0.2 \%$, and $26.3 \% \pm 0.1 \%$, respectively. The SPC components were determined according to the following literature methods: ISO 749 standard [18] for minerals, ISO 659 standard [19] for lipids, and the ADF-NDF method [20,21] for cellulose, hemicelluloses, and lignin. The content in water- 
soluble components was estimated by measuring the mass loss of the test sample after $1 \mathrm{~h}$ in boiling water. All analyses were carried out in duplicate.

\subsection{Fabrication of Extruded Pellets and Injection-Molded Pieces}

\subsubsection{Extruded Pellets}

The extruded pellets were obtained by destructuring and then plasticizing the proteins present in SPC. Thermo-mechano-chemical destructuring was carried out [22,23]. Protein plasticization was conducted in the presence of an aqueous solution of sodium sulfite $(1 \mathrm{~kg}$ sodium sulfite for $10 \mathrm{~kg}$ water) or even urea (U) using a Clextral (France) Evolum HT 53 co-rotating and co-penetrating twin-screw extruder (Figure 1). The latter was composed of nine modules, each 4D in length, $\mathrm{D}$ corresponding to the screw diameter (i.e., $53 \mathrm{~mm}$ ). The total barrel length was thus 36D (i.e., $1.908 \mathrm{~m}$ ).

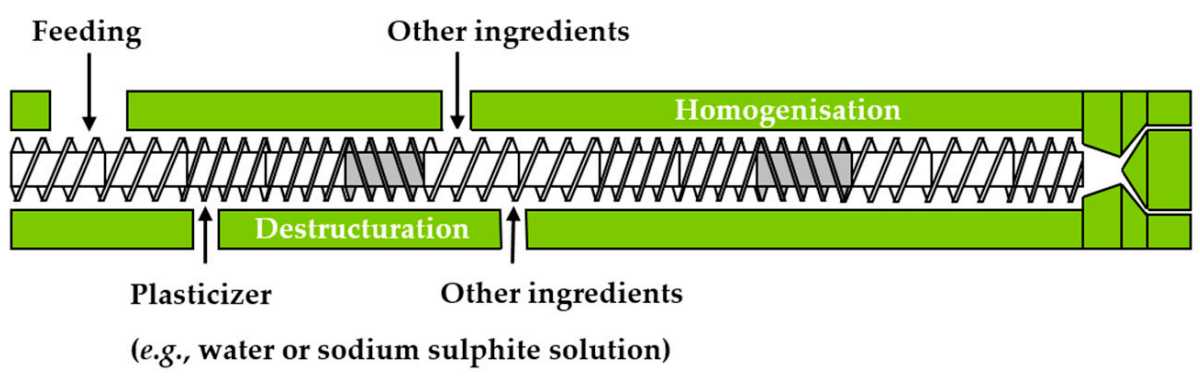

Figure 1. Twin-screw extrusion scheme.

The screw rotation speed was $300 \mathrm{rpm}$ for all the formulations produced. The temperature profile along the barrel was $20{ }^{\circ} \mathrm{C}$ for the feeding module (module 1 ), $80{ }^{\circ} \mathrm{C}$ for module 2 , and $100{ }^{\circ} \mathrm{C}$ for the seven other modules (i.e., modules 3 to 9 ).

SPC was introduced at the level of module 1 using a Coperion K-Tron (Coperion KTron (Schweiz) GmbH, Niederlenz, Switzerland) SWB 300-N weight feeder at a $64.5 \mathrm{~kg} / \mathrm{h}$ inlet flow rate. The sodium sulphite solution was injected at the end of the second module at a $23.3 \mathrm{~kg} / \mathrm{h}$ inlet flow rate using a DKM (Clextral, Firminy, France) Super K CAMP 112 piston pump. The resulting formulation was referred to as SPC. When incorporated in the formulation, BP and $U$ were also introduced at the level of module 1 using a Coperion K-Tron K-ML-KT20 weight feeder (Coperion K-Tron (Schweiz) GmbH, Niederlenz, Switzerland) at a $6.5 \mathrm{~kg} / \mathrm{h}$ inlet flow rate (i.e., $10 \%(w / w)$ in proportion to SPC). The corresponding formulations have been designated as follows: SPC-BP and SPC-U, respectively. For its part, the SPC-BP-U formulation was obtained by adding simultaneously BP and $U$ in module 1 , both introduced at a $3.25 \mathrm{~kg} / \mathrm{h}$ inlet flow rate.

The intimate mixing of the solids each other, and the impregnation of the liquid into the solid(s) was made possible by the use of two consecutive pairs of bilobe paddles (BL22 type), each 1D in length, positioned at the beginning of module 4 . The plasticization of sunflower proteins was obtained through intense mechanical shear using four consecutive pairs of reversed elements (CF2C type), each $0.5 \mathrm{D}$ in length, positioned at the end of module 7 and beginning of module 8 . A die equipped with six holes, each $3 \mathrm{~mm}$ in diameter, was positioned at the end of the barrel, and the extruded pellets were obtained using a Clextral HC 45 granulating system. They were then dried using a Clextral Evolum 600 continuous belt dryer up to a $10 \%$ moisture content before their packaging inside sealed plastic bags.

\subsubsection{Injection-Molded Pieces}

The extruded pellets were molded into standard bending and tensile specimens by thermoplastic injection using a Negri Bossi (Cologno Monzese, Italy) VE 160-720 machine with a clamping force of 160 ton, and a mold with two cavities. All formulations 
were rehydrated by adding water to the extruded pellets prior to thermoplastic injection. The moisture content of the extruded pellets was $20 \%$ at the time of molding.

The conditions used to produce the test specimens were as follows: $70^{\circ} \mathrm{C} / 90^{\circ} \mathrm{C} / 110^{\circ} \mathrm{C}$ for the temperature profile along the plasticizing screw, $130{ }^{\circ} \mathrm{C}$ for the temperature of the nozzle, $150 \mathrm{rpm}$ for the rotation speed of the plasticizing screw up to a $21 \mathrm{~mm}$ length for the shot building, 30 bar for the counter pressure, $150 \mathrm{~mm} / \mathrm{s}$ for the injection speed, 800 bar for the follow-up pressure applied during a $2.5 \mathrm{~s}$ duration, $1600 \mathrm{kN}$ for the clamping force, $50{ }^{\circ} \mathrm{C}$ for the mold temperature, and $20 \mathrm{~s}$ for the cooling time before opening the mold and ejecting the test specimens from the cavities.

Once obtained, the test specimens were placed in a climatic chamber at $60 \%$ relative humidity $(\mathrm{RH})$ and $25^{\circ} \mathrm{C}$ for three weeks for equilibration. Once equilibrated, they were then used for characterization.

\subsection{Characterization of Mechanical Properties and Water Sensitivity Test for SPC Composites}

\subsubsection{Density of Extruded Pellets and Injection-Molded Pieces}

The density of the extruded pellets was measured using a $50 \mathrm{~mL}$ pycnometer, and cyclohexane as immersion liquid. Cyclohexane was chosen because of its marked hydrophobic character. Indeed, cyclohexane contains only carbon and hydrogen atoms whose bonds are not polarized, thus classifying this solvent in the category of the apolar solvents. On the contrary, the granules are hydrophilic as they are composed of biomolecules and biopolymers with many polarized bonds (e.g., $\mathrm{CO}$ and $\mathrm{NH}$ bonds for proteins, $\mathrm{OH}$ bonds for cellulose, etc.). In consequence, there is no absorption of cyclohexane by the granules and no change in their volume by swelling. All determinations were carried out in duplicate.

The density of the injection-molded pieces was measured from three test specimens with an $80 \mathrm{~mm}$ length, a $10 \mathrm{~mm}$ width, and a $4 \mathrm{~mm}$ thickness. Their thickness and their width were measured at three points, and their length at two points, with a $0.01 \mathrm{~mm}$ resolution electronic digital sliding caliper. Thickness $(t)$, width $(b)$, and length $(l)$ mean values were recorded to calculate the specimen volume, and test specimens were all weighed to calculate their density $(d)$. Mean apparent density of the injection-molded pieces from the same formulation was the mean value of measurements made on the three test specimens.

\subsubsection{Resistance to Mechanical Abrasion}

The resistance to mechanical abrasion of both pellets and injection-molded pieces was estimated from an unstandardized test that was specifically developed during this study. For this test, a cylindrical plastic container having a $115 \mathrm{~mm}$ diameter and a $130 \mathrm{~mm}$ height was used. The bottom of the container was fixed to an axis, inclined at $15^{\circ}$ to the top with respect to the horizontal direction, and rotating by means of a motor at an $80 \mathrm{rpm}$ rotation speed. About $30 \mathrm{~g}$ of pellets or injection-molded pieces having a $10 \times 10 \times 4 \mathrm{~mm}^{3}$ volume were positioned inside the container before the beginning of the test. During the test, 10 metal parts for a total mass of $125 \mathrm{~g}$ were also placed inside the container, their addition aiming to simulate the mechanical abrasion to which the pellets or the injection-molded pieces will be subjected during their spreading to the field. Two wooden blades having the same length as the height of the container, both $1 \mathrm{~cm}$ high and $1 \mathrm{~cm}$ wide, were fixed inside the cylinder, $180^{\circ}$ to each other. Here, their objective was to amplify the effect of mechanical abrasion on the tested sample by the metal parts. The test duration was $1 \mathrm{~h}$. At the end of the test, the plant objects were recovered and then sieved on a $2 \mathrm{~mm}$ grid to quantify the fines generated during the mechanical abrasion test. The result was expressed as the ratio of fines to the initial mass of the sample analyzed (\%). The higher this ratio, the more sensitive the sample was to mechanical abrasion. All determinations were carried out in duplicate. 


\subsubsection{Tensile and Bending Properties}

The tensile properties of the injection-molded pieces were determined according to ISO 527-4 standard [24]. In particular, the two points chosen at the beginning of the stress-strain curve for the Young's modulus calculation were associated with the following elongations: 0.0005 (i.e., $0.05 \%$ ) and 0.0025 (i.e., $0.25 \%$ ).

The flexural properties were determined according to the ISO 178 standard [25], i.e., using the three points bending method. For both tensile and bending properties, an Instron (Instron, Norwood, MA, USA) 33R 4204 universal testing system fitted with a $5 \mathrm{kN}$ load cell was used.

The distance between jaws for the tensile tests was $105 \mathrm{~mm}$, and a testing speed of $3 \mathrm{~mm} / \mathrm{min}$ was applied. The grip separation for the bending tests was $40 \mathrm{~mm}$, and a testing speed of $2 \mathrm{~mm} / \mathrm{min}$ was applied. All determinations were carried out through four repetitions.

\subsubsection{Shore D Surface Hardness}

The Shore D surface hardness of the injection-molded pieces was determined according to the ISO 868 standard [26] with a Bareiss (Bareiss Prüfgerätebau GmbH, Oberdischingen, Germany) durometer. The indentation direction was perpendicular to the upper face of the injection-molded piece. For each formulation, determinations were carried out from four different bending test specimens, and measurements were made 10 times per each test specimen (five times for each of its sides).

\subsubsection{Water Sensitivity}

The water sensitivity of the injected pieces was determined according to ISO 16983 standard [27]. Measurements were conducted after soaking of the analysed samples in water during 1, 3, 6, and $24 \mathrm{~h}$, respectively. Thickness swelling (TS, \%) and water absorption (WA, \%) were calculated. All determinations were carried out in triplicate.

\subsection{Measurements of N Release from SPC Composites}

The study of the release of urea and other $\mathrm{N}$-containing compounds was performed according to a previously reported procedure [1]. The samples (4 g each) were immersed in $80 \mathrm{~mL}$ demineralized water in a $100 \mathrm{~mL}$ glass flask. Three replicates were carried out for each material. The flasks were stored at $25^{\circ} \mathrm{C}$ in the dark. At given sampling times $(1,2$, $4,10,15,25$ days), the liquid and solid phases were separated by centrifugation (15 $\mathrm{min}$ at $3000 \mathrm{rpm}$ ). The liquid phase was used for the determination of the concentrations of urea, ammonia, and total nitrogen with the methods described below. At each sampling, the same amount of demineralized water as that of the discarded supernatant was added to the solid phase.

\subsubsection{Determination of the Urea Concentration}

The concentration of urea in the supernatant was measured following the spectrophotometric method of Chen et al. [28]. One $\mathrm{ml}$ aliquot solution was diluted with water (1:1000 $(v / v)$ after 1 day extraction, 1:500 $(v / v)$ after 2, 4, and 7 days of extraction, 1:100 $(v / v)$ after 10 days of extraction, and 1:50 ( $v / v)$ after 15 and 25 days of extraction).

To the diluted samples $(18 \mathrm{~mL})$, transferred in a $100 \mathrm{~mL}$ amber glass bottles, $0.9 \mathrm{~mL}$ di DAM (diacetylmonoxime $0.5 \mathrm{~g} / 10 \mathrm{~mL}$ ), $0.15 \mathrm{~mL}$ TSC (thiosemicarbazide $0.2 \mathrm{~g} / 100 \mathrm{~mL}$ ), $\left.0.15 \mathrm{~mL} \mathrm{FeCl}_{3}, 6 \mathrm{H}_{2} \mathrm{O} 40.56 \mathrm{mg} / 100 \mathrm{~mL}\right), 12 \mathrm{~mL}(5 \%, v / v) \mathrm{H}_{2} \mathrm{SO}_{4}$ were added in sequence. The reaction mixtures were heated in a water bath at $80{ }^{\circ} \mathrm{C}$ for one hour.

The absorbance of the complex was measured at $520 \mathrm{~nm}$ in a spectrophotometer (Hitachi U-2000), previously calibrated with solutions of urea at given concentrations treated as described above. 


\subsubsection{Determination of Ammonia Nitrogen}

A $10 \mathrm{~mL}$ aliquot of the supernatant was transferred to a Kjeldahl tube. After addition of $1 \mathrm{~g} \mathrm{MgO}$ and $70 \mathrm{~mL}$ water, $\mathrm{NH}_{3}$ was distilled in a Kjeldahl instrument and collected in a beaker containing $20 \mathrm{~mL}$ boric acid and 2 drops of methyl red and bromocresol green indicator.

\subsubsection{Determination of Total Nitrogen}

A $1 \mathrm{~mL}$ aliquot of the supernatant was suspended in $25 \mathrm{~mL}$ sulfuric acid and $0.5 \mathrm{~g}$ selenic mixture and heated to boiling point until complete mineralization. The solution was transferred to a $25 \mathrm{~mL}$ volumetric flask and brought to volume with water. A $10 \mathrm{~mL}$ aliquot was transferred to a Kjeldahl tube and treated as above after addition of $40 \mathrm{~mL} 40 \%$ $\mathrm{NaOH}$ instead of $\mathrm{MgO}$.

\subsubsection{Determination of Organic Nitrogen}

Organic nitrogen was calculated by subtracting ammonia and urea $\mathrm{N}$ from total $\mathrm{N}$.

\subsection{Statistical Treatment of Data}

The data were evaluated by one-way ANOVA $(p<0.05)$ followed by the Tukey's test for multiple comparison procedures.

\section{Results}

\subsection{The Twin-Screw Extrusion Process to Manufacture the SPC-Based Composite Pellets}

A process was patented [22], in which a material rich in protein, such as sunflower or rapeseed oil cake, can be rendered thermoplastic, capable of being injected at about $120^{\circ} \mathrm{C}$. This is achieved by previously destructuring the oil cake in a continuous twin-screw extruder, while adding an appropriate plasticizer (Figure 1). The most interesting part of the invention is that water can act as plasticizer, which is a neat environmental advantage. The extrusion process, followed by an injection process, allowed obtaining biodegradable planting pots [29].

A further improvement in the process of plasticizing sunflower proteins by thermomechano-chemical destructuring in a twin-screw extruder consists of adding a sodium sulphite salt to the water in such a way that the proportion of sodium sulphite is between 1 and $10 \mathrm{~g}$ per $100 \mathrm{~g}$ of protein [23]. In addition to the plasticizing effect of water, sodium sulfite allows a reduction of the disulphide covalent bonds linking the amino residues of cysteine together. Proteins are thus further destructured, and the melt rheology of the obtained agro-granulates is reduced. This makes it easier to produce thermoplastic injection-molded articles.

Another process was also patented for the production of water soluble SPC from industrial SOC reacted in alkaline water at $\mathrm{pH} 12$ and $50{ }^{\circ} \mathrm{C}$ [30]. By this procedure, the SPC contains $90 \%$ protein, $1.7 \%$ lignin, no polysaccharide, and $2.4 \%$ ash against $34 \%$ protein, $32 \%$ polysaccharides, $5.2 \%$ lignin, and $7.6 \%$ ash in the pristine material. The SPC protein isolate could be relevant in the present work for two reasons. Its thermoplastic properties allow using it as matrix for the manufacture of extruded articles from blends with additives, which have no film forming properties or cannot be processed by extrusion. In addition to the matrix plastic properties, the SPC content of N [31], and of P and K [32], adds the capability to perform also as plant nutrient and/or biostimulant [33] release agent in CRF agriculture applications.

In the present work, twin-screw extrusion and injection-molding were carried out from a sunflower protein concentrate (SPC) having a 51\% content in proteins. Figure 2 describes a schematic diagram of the process developed for the preparation of the fertilizers. First, the extrusion tool was used with success to conduct the thermo-mechano-chemical destructuring of SPC, thus allowing the protein plasticization. The latter was effective thanks to the addition of the sodium sulfite solution, water acting as a plasticizer for proteins [8] on the one hand and the sodium sulfite salt as a reducing agent for the disulfide bonds, i.e., 
the cysteine bridges [23], on the other hand. In addition, thanks to the high versatility of the twin-screw extrusion technology [34], the simultaneous addition of BP and/or U in the same twin-screw extruder pass resulted in the unexpected synergic intensification of the developed process. All the obtained formulations (i.e., SPC, SPC-U, SPC-BP, and SPC-BP-U) were produced in a controlled way as shown by the stability of the current consumed by the motor of the twin-screw machine throughout the sampling process.

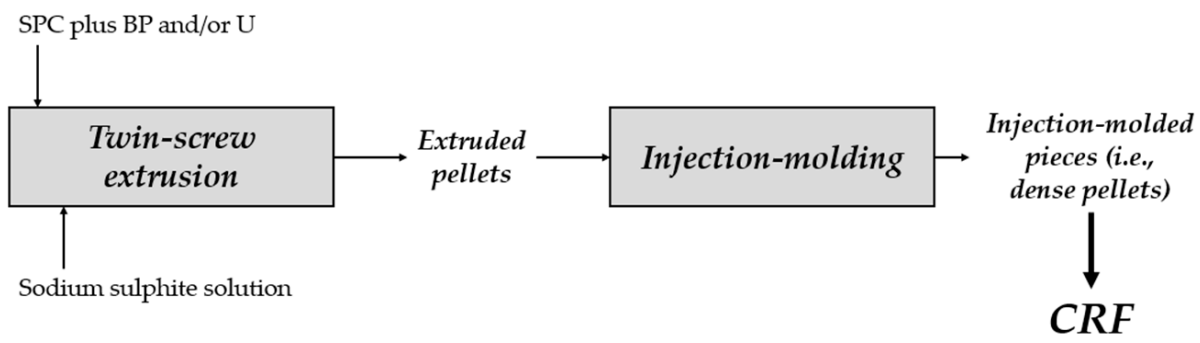

Figure 2. Schematic diagram of the process developed for the preparation of the fertilizers.

However, for the two formulations including BP (i.e., SPC-BP and SPC-BP-U), it has to be noted that a significant self-heating of the mixture was observed in the die (up to $113{ }^{\circ} \mathrm{C}$ instead of $96-104{ }^{\circ} \mathrm{C}$ without BP). This resulted in higher electric current (up to $66 \mathrm{~A}$ instead of 41-46 A), higher specific mechanical energy (up to $143 \mathrm{~W} \cdot \mathrm{h} / \mathrm{kg}$ instead of $89-108 \mathrm{~W} \cdot \mathrm{h} / \mathrm{kg}$ ), and higher pressure at the die (up to 14.9 bar instead of $6.0-7.5 \mathrm{bar}$ ). The self-heating resulted also in lower moisture content of the SPC-BP and SPC-BP-U extruded pellets (up to $14.3 \%$ instead of $26.2-26.7 \%$ ) at the twin-screw extruder outlet, being associated with a $60 \%$ water evaporation during the extrusion process instead of no more than $17 \%$ for the two other formulations (i.e., SPC and SPC-U). For future work, it will be therefore necessary to be aware of the risk of abrasive wear on the screw elements and the inner walls of the twin-screw extruder barrel during the production of large quantities of BP-based extruded pellets.

Due to the rehydration of the extruded pellets up to $20 \%$ moisture content before shaping, the injection-molding of the test specimens was possible for all the formulations tested. Indeed, the correct filling of the mold cavities was always effective, including for the BP-based products that generated self-heating in extrusion. Immediately after injection-molding, tensile and bending test specimens were positioned in a climatic chamber for conditioning. A three-week duration was required for complete equilibration (i.e., for obtaining a constant weight for the specimens).

\subsection{Composition of the SPC-Based Composites}

Table 1 reports the C, N, P, K content for the SPC-U, SPC-BP, and SPC-BP-U composite pellets fabricated in the present work and for the neat SPC, U, BP components used in the fabrication of the composite pellets. All three components contain N. Differently from synthetic urea, SPC and BP originating from natural renewable materials also contain the two additional $\mathrm{P}$ and $\mathrm{K}$ plant nutrient elements inherited from the pristine sources. It may be observed that the N content in the pellets decreases significantly in the order SPC-U > SPC-BP-U > SPC-BP = SPC. The K content of the SPC-BP pellets is significantly higher than the $\mathrm{K}$ content in the other three pellets, as result of the $\mathrm{K}$ content in the neat BP sample, being nearly four times higher than the K content in the neat SPC pellet. The data confirm that during the pellets manufacture no degradation of the neat components occurs. 
Table 1. Total C, N, P, and K concentrations $(\%, w / w)$ in neat sunflower protein concentrate (SPC), biopolymer (BP), urea (U), and in the SPC pellets' samples ${ }^{1}$.

\begin{tabular}{ccccc}
\hline Formulation & $\mathbf{C}$ & $\mathbf{N}$ & $\mathbf{P}_{\mathbf{2}} \mathbf{O}_{\mathbf{5}}$ & $\mathbf{K}_{\mathbf{2}} \mathbf{O}$ \\
\hline BP & 39.6 & 6.59 & 1.14 & 5.5 \\
U & 20.0 & 46.6 & - & - \\
SPC & $38.7 \pm 5.2^{\mathrm{a}}$ & $6.9 \pm 0.9^{\mathrm{a}}$ & $2.5 \pm 0.1^{\mathrm{a}}$ & $1.5 \pm 0.1^{\mathrm{a}}$ \\
SPC-U & $37.7 \pm 0.2^{\mathrm{a}}$ & $10.5 \pm 0.1^{\mathrm{b}}$ & $2.3 \pm 0.1^{\mathrm{a}}$ & $1.3 \pm 0.1^{\mathrm{a}}$ \\
SPC-BP & $39.5 \pm 2.6^{\mathrm{a}}$ & $7.0 \pm 0.6^{\mathrm{a}}$ & $2.6 \pm 0.3^{\mathrm{a}}$ & $1.8 \pm 0.1^{\mathrm{b}}$ \\
SPC-BP-U & $38.6 \pm 0.4^{\mathrm{a}}$ & $8.5 \pm 0.0^{\mathrm{c}}$ & $2.1 \pm 0.1^{\mathrm{a}}$ & $1.5 \pm 0.1^{\mathrm{a}}$ \\
\hline
\end{tabular}

${ }^{1}$ Values in the same column followed by different letters $(\mathrm{a}-\mathrm{c})$ are significantly different $(p<0.05)$.

\subsection{Mechanical Properties of the SPC-Based Composites}

Table 2 reports the density of the extruded pellets and the injection-molded pieces from formulations SPC, SPC-U, SPC-BP, and SPC-BP-U. For the extruded pellets, those containing $\mathrm{U}$ and /or BP appear denser than those related to the SPC formulation. Urea contributes more to the densification of the pellets than BP. A very clear densification is observed for all the formulations tested after the shaping step, with the density of the injection-molded pieces remaining relatively independent of the formulation $\left(1362-1398 \mathrm{~kg} / \mathrm{m}^{3}\right)$.

Table 2. Density $\left(\mathrm{kg} / \mathrm{m}^{3}\right)$ of the extruded pellets and the resulting injection-molded pieces.

\begin{tabular}{ccc}
\hline Formulation & Extruded Pellets & Injection-Molded Pieces \\
\hline SPC & $783.2 \pm 4.1$ & $1383.2 \pm 10.0$ \\
SPC-U & $1122.5 \pm 29.4$ & $1398.2 \pm 4.5$ \\
SPC-BP & $878.2 \pm 29.9$ & $1384.9 \pm 2.7$ \\
SPC-BP-U & $998.7 \pm 26.9$ & $1361.8 \pm 19.2$ \\
\hline
\end{tabular}

Table 3 reports the results for the resistance to mechanical abrasion for both extruded pellets and injection-molded pieces from formulations SPC, SPC-U, SPC-BP, and SPC-BP-U. These results show a poor abrasion resistance of the extruded pellets, especially those containing neither $\mathrm{U}$ nor $\mathrm{BP}$, which results in the generation of a high proportion of fines during the test. In the presence of one of these additives, the abrasion sensitivity of the pellets is reduced, especially for those containing urea. However, the generation of fines is still important in that case, i.e., at least $11.5 \%$ (case of the SPC-U formulation). On the opposite, the densification of the materials during the injection-molding step contributes to a very good resistance to mechanical abrasion, with the number of fines generated never exceeding $0.7 \%(w / w)$.

Table 3. Resistance to mechanical abrasion of the extruded pellets and the resulting injection-molded pieces (\% of fines, $w / w)$.

\begin{tabular}{ccc}
\hline Formulation & Extruded Pellets & Injection-Molded Pieces \\
\hline SPC & $68.8 \pm 1.6$ & $0.6 \pm 0.0$ \\
SPC-U & $11.5 \pm 3.0$ & $0.4 \pm 0.0$ \\
SPC-BP & $55.9 \pm 2.4$ & $0.4 \pm 0.0$ \\
SPC-BP-U & $32.5 \pm 2.1$ & $0.7 \pm 0.1$ \\
\hline
\end{tabular}

Tables 4 and 5 present the tensile and bending properties, respectively, of the injectionmolded pieces made from the SPC, SPC-U, SPC-BP, and SPC-BP-U formulations. In parallel, Figure 3 represents the mean stress-strain curves obtained during the tensile tests, and Figure 4 the mean load-displacement ones obtained during the bending tests. These results reveal a reduction in the rigidity of the injection-molded pieces when $\mathrm{U}$ and/or BP are contained inside the formulation, especially for the SPC-U formulation. This is illustrated by the decreases in the elastic modules (Tables 4 and 5), which also results in a reduction 
in the gradient of the curves at their origin (Figures 3 and 4). Additionally, an increase in the elongation at break is observed during the tensile tests, especially for the SPC-U formulation. The same result is also evidenced for the displacement at rupture during the bending tests.

Table 4. Tensile properties ${ }^{1}$ of the injection-molded pieces.

\begin{tabular}{cccccc}
\hline Formulation & $\mathbf{E}_{\mathbf{y}} \mathbf{( M P a )}$ & $\boldsymbol{\sigma}_{\max }(\mathbf{M P a})$ & $\varepsilon_{\max }(\mathbf{\%})$ & $\boldsymbol{\sigma}_{\mathbf{r}}(\mathbf{M P a})$ & $\varepsilon_{\mathbf{r}}(\mathbf{\%})$ \\
\hline SPC & $1490 \pm 120$ & $8.2 \pm 1.7$ & $0.9 \pm 0.4$ & $7.8 \pm 2.6$ & $0.9 \pm 0.4$ \\
SPC-U & $476 \pm 210$ & $6.4 \pm 1.0$ & $4.3 \pm 3.2$ & $6.4 \pm 1.1$ & $4.4 \pm 3.3$ \\
SPC-BP & $858 \pm 321$ & $6.0 \pm 1.6$ & $1.3 \pm 1.0$ & $5.8 \pm 1.9$ & $1.3 \pm 1.0$ \\
SPC-BP-U & $497 \pm 77$ & $4.6 \pm 1.3$ & $1.3 \pm 0.5$ & $4.6 \pm 1.3$ & $1.3 \pm 0.5$ \\
\hline
\end{tabular}

\footnotetext{
${ }^{1} \mathrm{E}_{\mathrm{y}}$, Young's modulus; $\sigma_{\max }$, maximal tensile strength; $\varepsilon_{\max }$, elongation at maximal tensile strength; $\sigma_{\mathrm{r}}$, tensile strength at rupture; $\varepsilon_{\mathrm{r}}$, elongation at rupture.
}

Table 5. Bending properties ${ }^{1}$ of the injection-molded pieces.

\begin{tabular}{cccc}
\hline Formulation & $\mathbf{E}_{\mathbf{f}}(\mathbf{M P a})$ & $\boldsymbol{d}_{\mathbf{r}}(\mathbf{m m})$ & $\boldsymbol{\sigma}_{\mathbf{f}}(\mathbf{M P a})$ \\
\hline SPC & $1471 \pm 85$ & $1.2 \pm 0.2$ & $20.6 \pm 3.9$ \\
SPC-U & $295 \pm 20$ & $6.7 \pm 1.4$ & $14.0 \pm 1.3$ \\
SPC-BP & $434 \pm 69$ & $3.2 \pm 0.2$ & $13.3 \pm 2.5$ \\
SPC-BP-U & $716 \pm 34$ & $2.0 \pm 0.1$ & $14.9 \pm 0.8$ \\
\hline
\end{tabular}

${ }^{1} \mathrm{E}_{\mathrm{f}}$, bending modulus; $d_{\mathrm{r}}$, displacement at rupture; $\sigma_{\mathrm{f}}$, flexural strength at break.

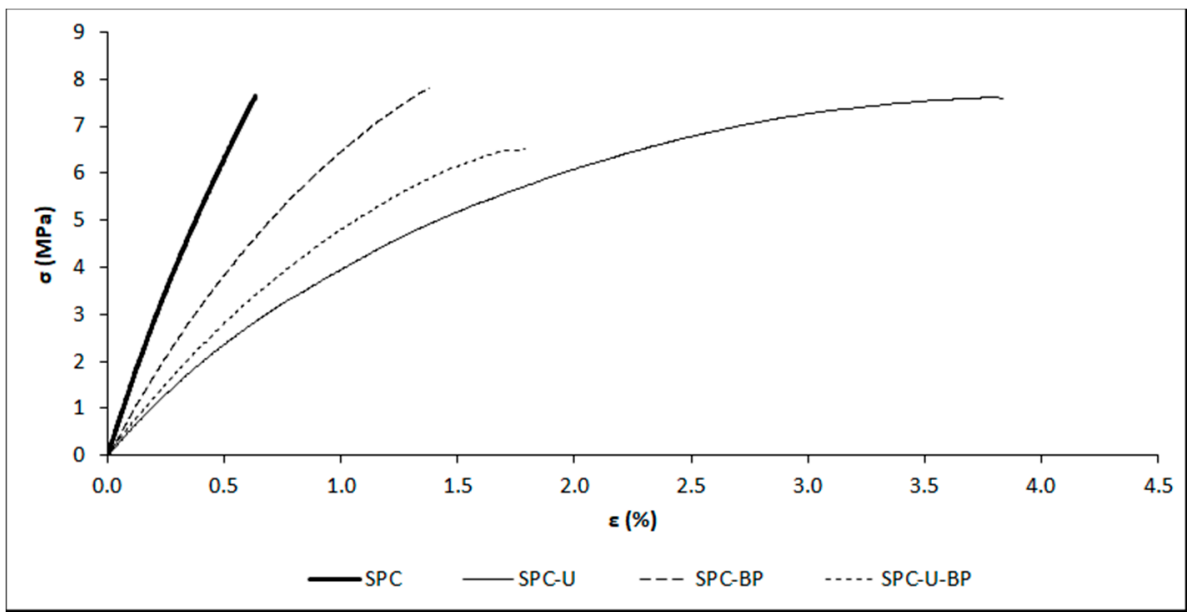

Figure 3. Mean stress-strain curves obtained during the tensile test conducted on the injectionmolded pieces.

Table 6 reports the Shore D surface hardness results. Compared to the SPC injectionmolded product, a slight reduction in the surface hardness is observed for the SPC-U formulation. On the contrary, it is clear that the addition of BP inside SPC contributes to much harder injection-molded pieces on their surface.

Table 6. Shore D surface hardness of the injection-molded pieces.

\begin{tabular}{cc}
\hline Formulation & Shore D $\left(^{\circ}\right)$ \\
\hline SPC & $52.1 \pm 3.4$ \\
SPC-U & $46.9 \pm 2.4$ \\
SPC-BP & $73.2 \pm 2.3$ \\
SPC-BP-U & $62.0 \pm 3.5$ \\
\hline
\end{tabular}




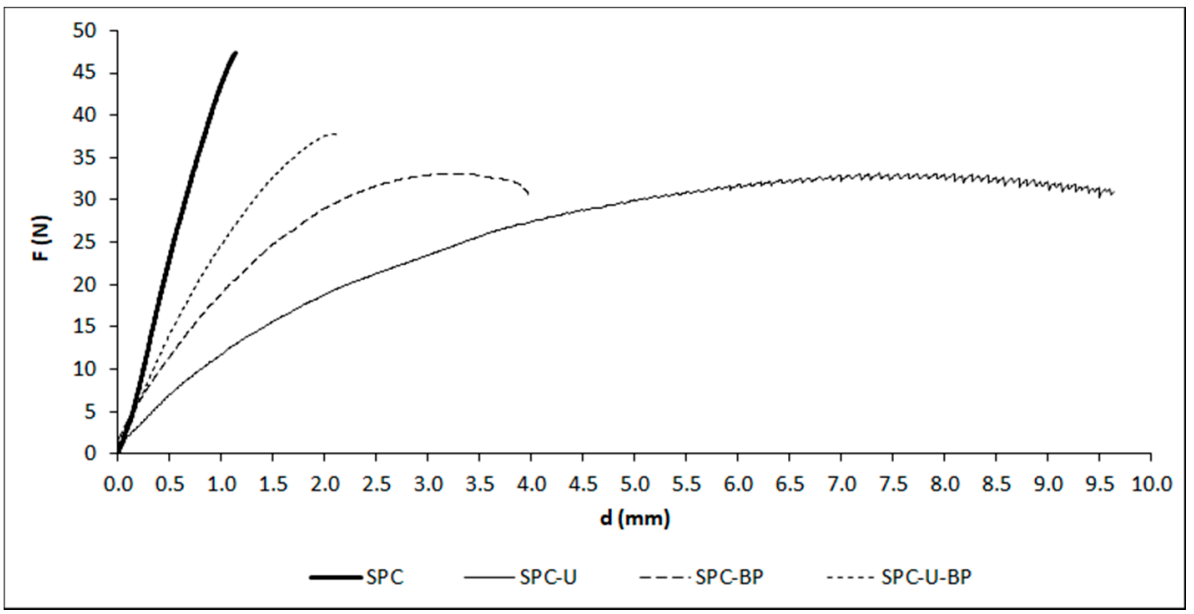

Figure 4. Mean load-displacement curves obtained during the bending test conducted on the injection-molded pieces.

To complete the mechanical characterization of the composites, the latter were also tested with respect to their water resistance after immersion in water during $1,3,6$, and $24 \mathrm{~h}$. TS and WA values were determined after immersion, and the results are mentioned in Figures 5 and 6, respectively. A progressive increase in the water absorption is observed with the increasing soaking duration for all the tested formulations, with the WA mean value ranging from $45 \%$ after $1 \mathrm{~h}$ immersion to $158 \%$ after $24 \mathrm{~h}$. However, the SPC materials are those with the lowest WA values, regardless of the immersion duration. In parallel, after $1 \mathrm{~h}$ immersion in water, thickness swelling is much lower for the SPC and SPC$\mathrm{U}$ formulations ( $30 \%$ in average for TS), compared to the two others ( $41 \%$ in average). TS continues to increase for longer soaking durations, and it remains in the same order of magnitude for all the tested formulations after $3 \mathrm{~h}$ just as $6 \mathrm{~h}$ (52\% in average). After $24 \mathrm{~h}$, SPC, SPC-U, and SPC-BP formulations are so impregnated with water and so fragile when handled that their TS is no longer measurable.

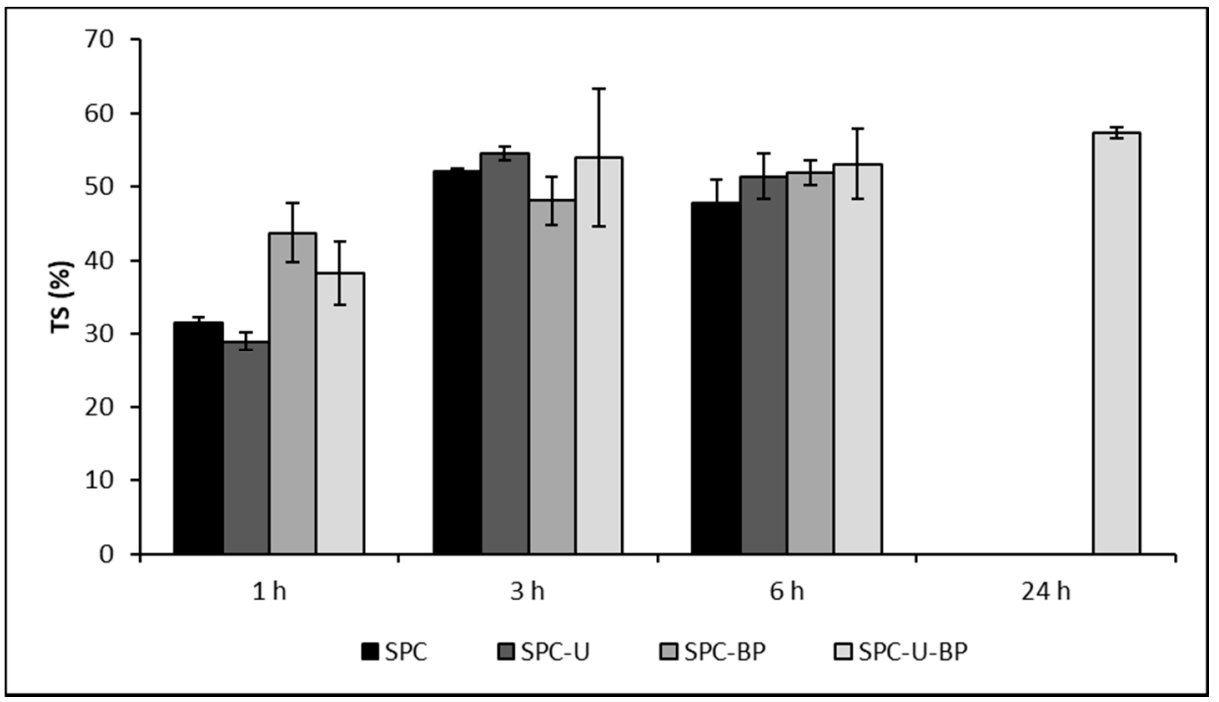

Figure 5. Thickness swelling (TS) of the injection-molded pieces after immersion in water. 


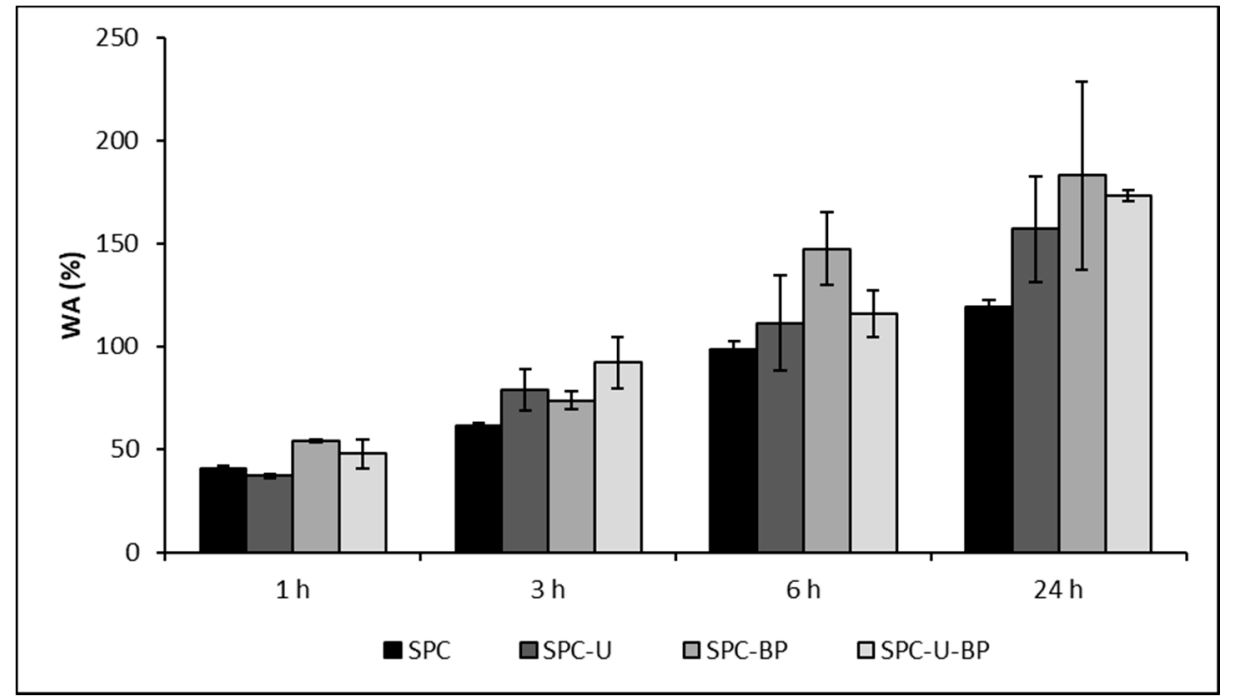

Figure 6. Water absorption (WA) of the injection-molded pieces after immersion in water.

\subsection{Urea, Ammonia, and Total N Release from the Composite SPC-Based Pellets}

The release of water solubles from the SPC injection-molded pieces is visually appreciated in Figure 7 by the color of the solution becoming darker upon increasing the water contact time.

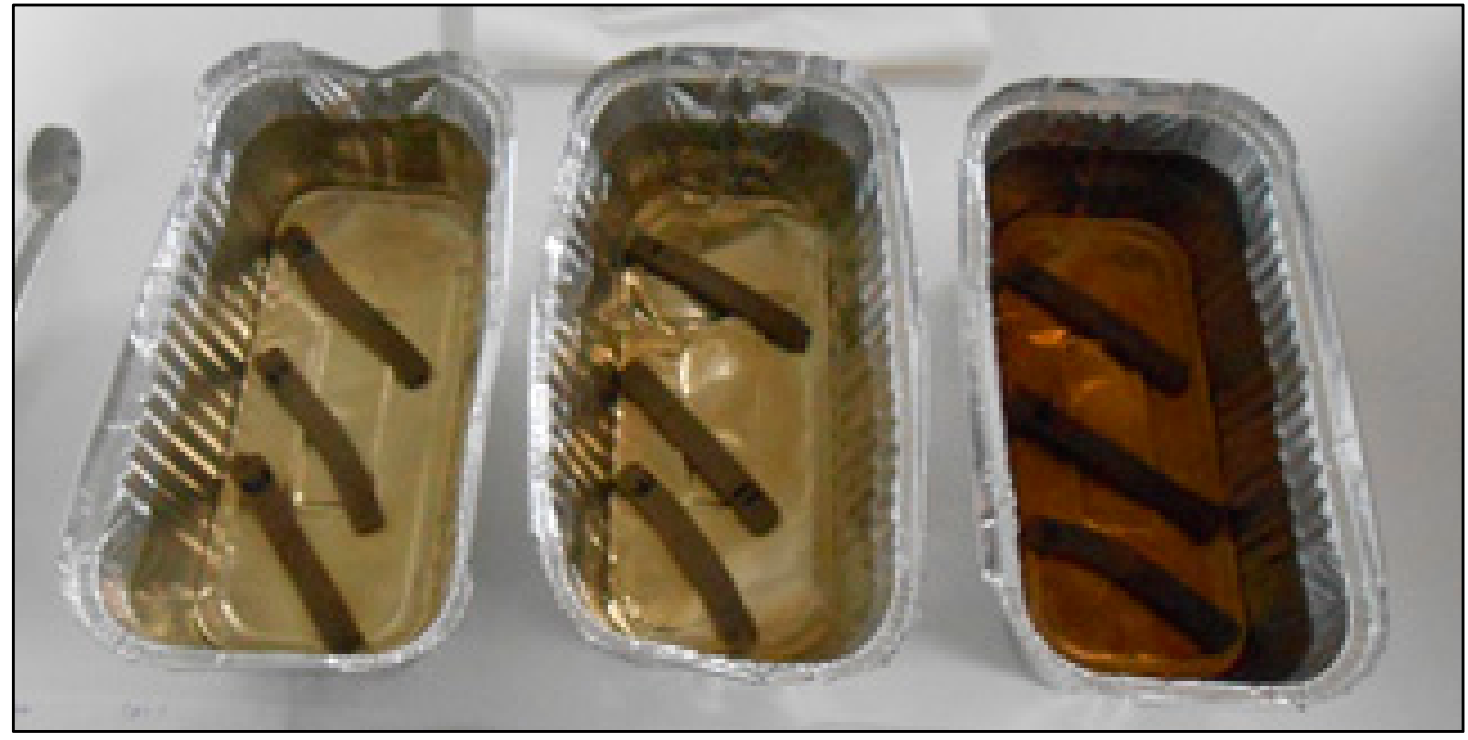

Figure 7. Macroscopical image illustrating the change of the visual of the SPC injection-molded piece-water system upon increasing the solid-liquid contact time (from left to right, 1, 3, and $6 \mathrm{~h}$ ).

Table 7 reports the total $\mathrm{N}$ released in solution from the pellets after 25 days' contact time with water, as \% of the initial N. The data were calculated from the experimental $\mathrm{N}$ values measured in solution and from the experimental $\mathrm{N}$ values measured in the residual solid pellet. Considering the standard deviation values, for each pellet, the two methods give the same values. This validates the analytical procedure adopted to assess the performance of the pellets as CRF. 
Table 7. $\mathrm{N}$ mass balance (comparison of $\%$ total $\mathrm{N}$ in solution measured by mineralization and Kjeldahl analysis, and \% total $\mathrm{N}$ in the solid samples measured by elemental analysis) ${ }^{1}$.

\begin{tabular}{ccc}
\hline Formulation & \% of Initial N, Measured in Solution & $\begin{array}{c}\text { \% of Initial N, Calculated on the } \\
\text { Basis of the Initial and Final Weight } \\
\text { and N Concentration of the Samples }\end{array}$ \\
\hline SPC & $46.1 \pm 6.1^{\mathrm{a}}$ & $59.9 \pm 10.0^{\mathrm{a}}$ \\
SPC-U & $79.4 \pm 7.4^{\mathrm{b}}$ & $72.7 \pm 2.1^{\mathrm{a}}$ \\
SPC-BP & $60.5 \pm 9.9^{\mathrm{a}}$ & $68.7 \pm 15.7^{\mathrm{a}}$ \\
SPC-BP-U & $82.0 \pm 2.5^{\mathrm{b}}$ & $71.8 \pm 11.9^{\mathrm{a}}$
\end{tabular}

${ }^{1}$ Values in the same column followed by different letters $(a, b)$ are significantly different $(p<0.05)$.

The cumulative urea release in solution from the urea loaded pellets is illustrated in Figure 8 . It is about $3 \%$ and $1.5 \%$ of the initial urea content of SPC-BP-U and SPC-U, respectively. The initial urea was 5\% in the SPC-BP-U and 10\% in the SPC-U sample. At the end of the release experiment, the concentration of urea was less than $1 \%$ of the total $\mathrm{N}$ content in both pellets. Thus, the loss of urea from the SPC-U pellet was about twice that from the SPC-BP-U sample. Yet, the cumulative urea released from the SPC-U sample was half that released from the SPC-BP-U sample. The two pellets were tested under the same conditions, i.e., $4 \mathrm{~g}$ pellet sample in $80 \mathrm{~mL}$ water. The apparent inconsistency of the release experimental data in Figure 8 suggests two plausible explanations. The relatively low and constant cumulative urea release suggests that, besides its slow release, urea is promptly hydrolyzed to ammonia $[35,36]$. The higher cumulative urea release found for the SPC-BP-U sample may suggest that BP acts as inhibitor of urea hydrolysis. Inhibition of urea hydrolysis implies reduction of ammonia formation. These effects are in agreement with a recent paper [37] reporting that BP reduces the emission of ammonia from animal urine by $30 \%$.

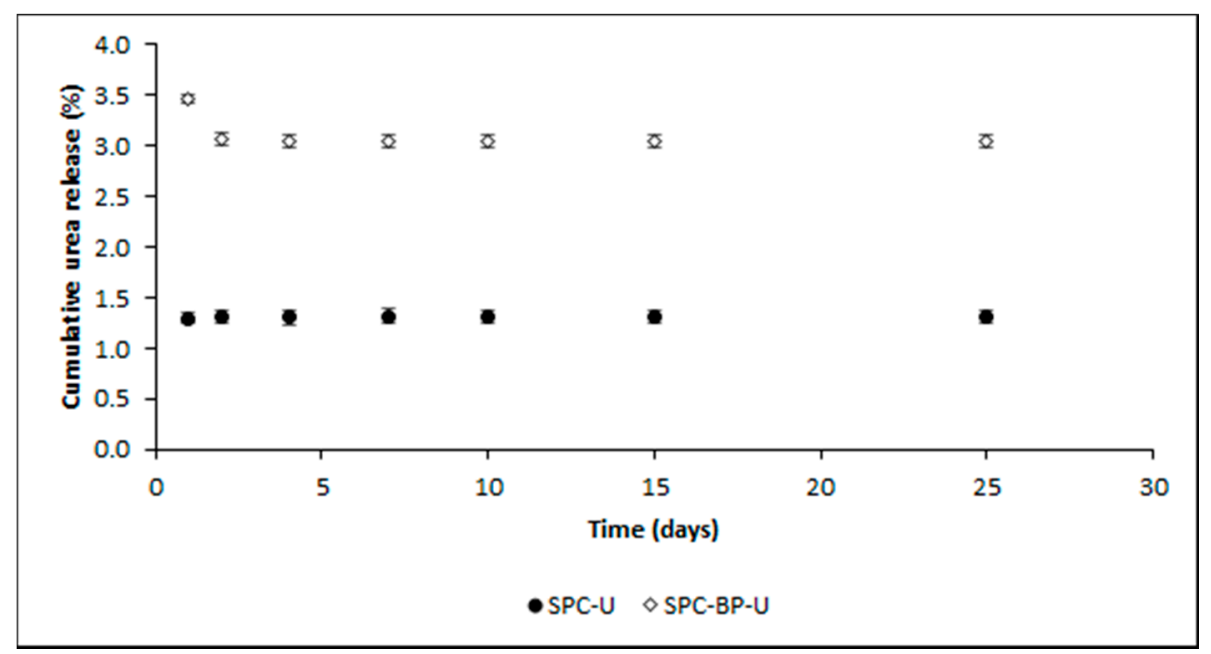

Figure 8. Cumulative urea $\mathrm{N}$ released expressed as percentage of the initial urea content.

Table S1 (see Supplementary Material) reports the calculated amount of $\mathrm{N}$ from each component $\left(\mathrm{N}_{\mathrm{SPC}}, \mathrm{N}_{\mathrm{BP}}\right.$ and $\mathrm{N}_{\mathrm{U}}$ ) in the blended SPC-U and SPC-BP-U pellets. Based on the residual amount of urea in the pellets at the end of the experiments, one can calculate that the urea release is $88 \%$ from SPC-U and 61\% from SPC-BP-U. Based on Figure 8, these amounts of urea appear released within the first day. However, due to the rapid hydrolysis of urea, this cannot be assessed. Other workers did not report such rapid hydrolysis. For urea coated with 10-20\% Kraft lignin [13], the increase of urea release upon increasing time was much less steep than that in Figure 8. The former was almost linear over the 15 days' duration of the experiment, during which time the investigated material released $80 \%$ of its initial urea content. Urea granules coated with $20 \%$ mix made 
of polyvinyl alcohol and other natural biodegradable polymers [36] showed a similar pattern as in Figure 8, but they released 100\% urea within 15-120 min.

Under the above circumstances, total $\mathrm{N}$, ammonia $\mathrm{N}$, and organic $\mathrm{N}$ were found better indicators of the behavior of the SPC composite pellets as CRFs.

\subsection{Release of $N$ in Solution as Ammonia}

The release of $\mathrm{N}$ as ammonia, expressed as percentage of the initial $\mathrm{N}$ amount, is illustrated in Figure 9. The plot pattern is much less steep than that in Figure 8. In the first days of the experiment, the samples containing urea, SPC-U and SPC-BP-U, released more ammonia than the other two. After seven days, the data were affected by a large variability therefore no significant differences between the samples could be appreciated. In all samples, after 25 days, about $10 \%$ of the initial $\mathrm{N}$ amount was released as ammonia.

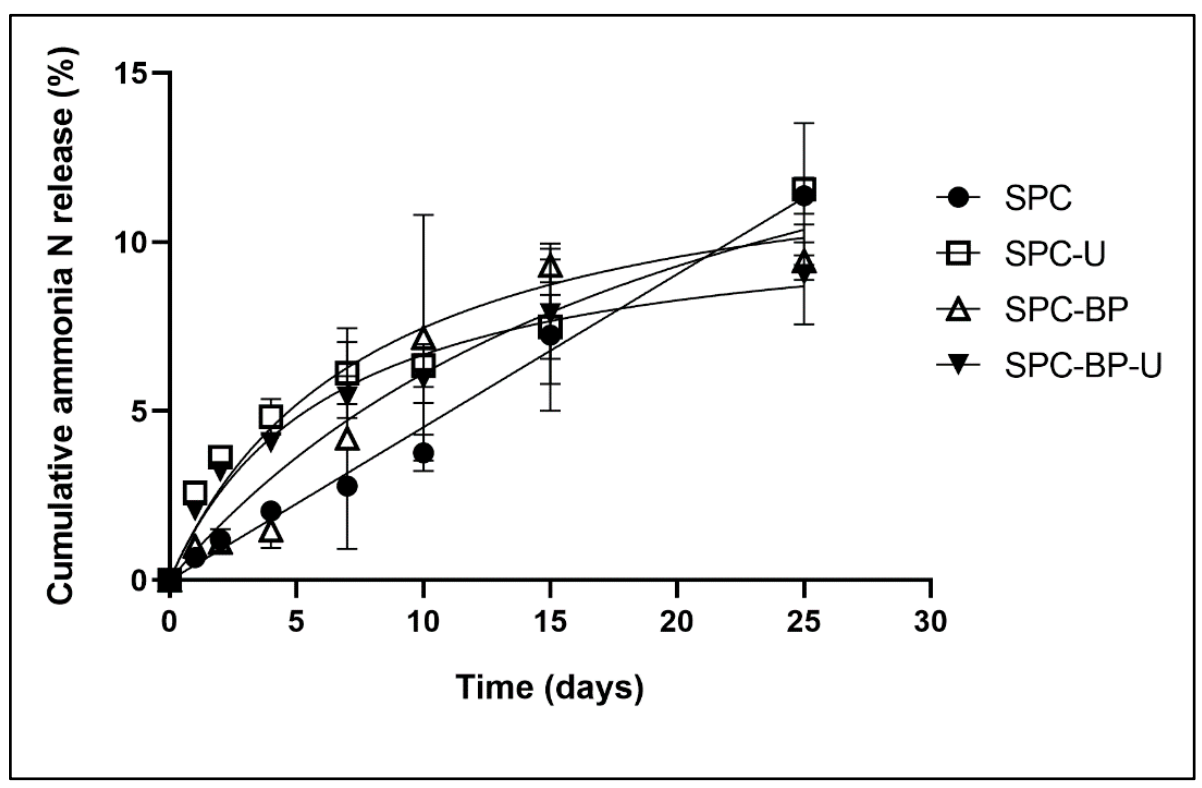

Figure 9. Percentage of initial $\mathrm{N}$ released in solution as ammonia.

The results indicate that in the first five days, urea was the main source of ammonia. In the same period of time, the release of ammonia from the SPC-BP-U sample is shown lower than that from the SPC-U sample. This fact supports the hypothesis of BP inhibiting the hydrolysis of urea. It is therefore consistent with the higher release of urea shown in Figure 8.

On the other hand, the lack of difference of the cumulative ammonia release among all samples at the end of the experiments suggests that hydrolysis of other $\mathrm{N}$-containing compounds, likely the proteins of the sunflower cake, was the main source of ammonia. Indeed, while the release of ammonia from SPC was significantly the lowest until day 10, at longer contact time with water, SPC ends up releasing the same amount of ammonia as SPC-U. This confirms that part of the SPC proteins is converted into ammonia.

The data indicate that the rate of solubility and nitrogen mineralization of the three pellets components follows the order $\mathrm{U}>\mathrm{BP}>\mathrm{SPC}$. The slowest rates exhibited by BP and SPC, compared to urea, is reasonably expected as these samples contain protein matter, which has first to dissolve in water, then be hydrolyzed to amino acids (AA), before the conversion of $\mathrm{N}$ from AA into ammonia.

\subsection{Release of Total and Organic $N$ in Solution}

Figure 10 shows the plots of the cumulative total $\mathrm{N}$ release in solution. The total $\mathrm{N}$ data are far greater than the $\mathrm{N}$ release values as ammonia in Figure 9. This shows that most of the total N in solution is organic N. As the SPC content in the pellet samples is $90 \%$, 
most of the organic $\mathrm{N}$ in solution must be contributed from solubilization of SPC. Indeed, based on the $4 \mathrm{~g}$ sample weight (see Materials and Methods), on the pellets' formulations, and on Table 1 and Figure 10 data, one can calculate that the total N release from the SPC-U, SPC-BP, and SPC-BP-U pellets was always much higher than the amount of N contributed by both $\mathrm{BP}$ and $\mathrm{U}$ in the starting composite pellets (Table S1).

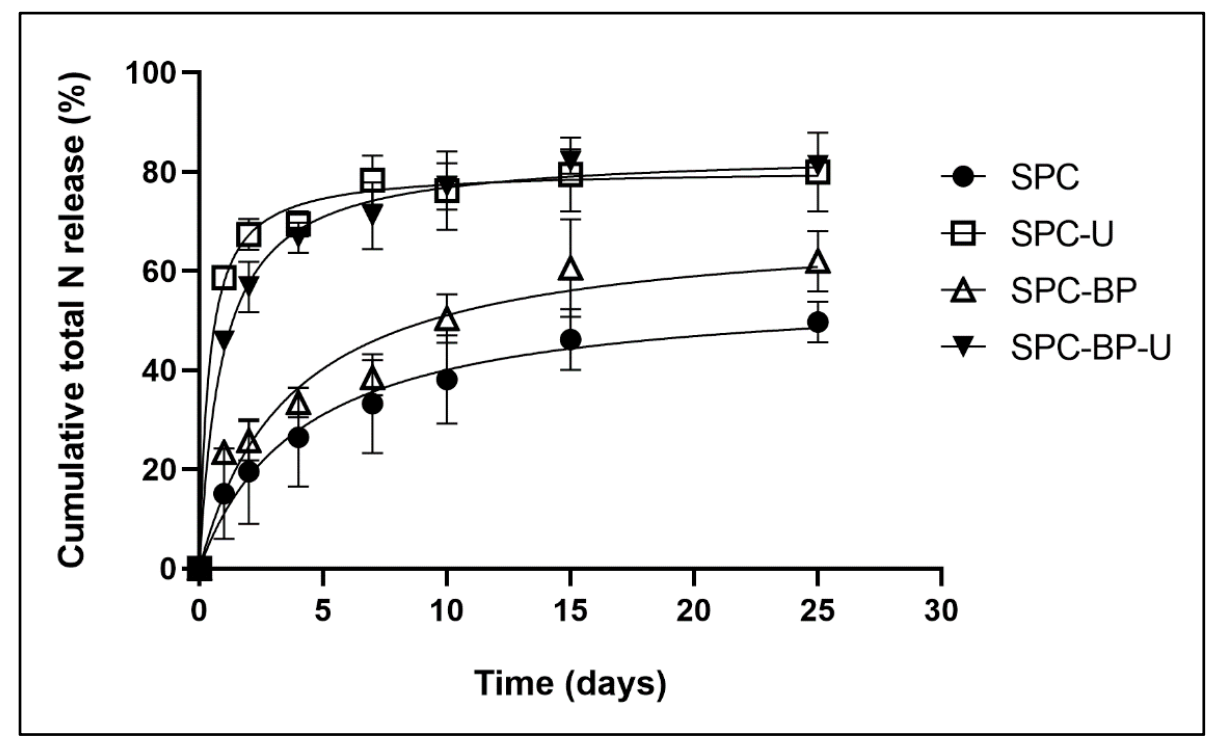

Figure 10. Percentage of initial $\mathrm{N}$ released in solution as total $\mathrm{N}$.

The plots in Figure 10 reflect the above order of solubility/N mineralization for the three samples formulations, which is indicated by the cumulative ammonia release plots in Figure 9. The total $\mathrm{N}$ release data clearly point out the difference between the pellets containing urea and the pellets containing no urea. SPC sample released $13.4 \% \mathrm{~N}$ in $24 \mathrm{~h}$ and $49.7 \% \mathrm{~N}$ in 25 days. This sample meets the requirements [1] for a slow-release fertilizer: No more than 15\% released in $24 \mathrm{~h}$, no more than $75 \%$ released in 28 days at $25{ }^{\circ} \mathrm{C}$. The SPC-BP sample is close to this behavior, except for the $24 \mathrm{~h}$ release, which was $23.4 \%$. The urea-containing samples tended to release $\mathrm{N}$ more rapidly than the others all over the experiment, especially within the first day $(45.8 \%$ and $58.7 \%$ for SPC-BP-U and SPC-U, respectively). After 25 days, the total $\mathrm{N}$ found in solution was about $80 \%$ of the initial amount. These results are close to those reported by other workers [38] in a similar experiment, conducted with urea-impregnated woodchips (U-WC) having the same C and $\mathrm{N}$ contents as the SPC composite pellets (Table 1). The cumulative $\mathrm{N}$ release pattern of the urea-impregnated woodchips was similar to that of the SPC composite pellets in Figure 10. The U-WC released $40 \% \mathrm{~N}$ in solution, relative to the initial $\mathrm{N}$ content in the solid material, after $24 \mathrm{~h}$, nearly $60 \% \mathrm{~N}$ after 4 days, and 62-68\% $\mathrm{N}$ after 32 days, depending on the nature of the woody material. Statistically, at the end of the experiment, all above SPC samples yield total $\mathrm{N}$ release after 24 days within the above highest $75 \%$ limit. Thus, all four sample formulations may be classified as controlled-release fertilizers.

Figure 11 shows that both BP and, much more so, urea enhance the organic $\mathrm{N}$ release, compared to the neat SPC pellet. The behavior of the SPC-BP sample is very interesting. In the first 10 days, the total organic release from SPC-BP is not much different from that of the neat SPC pellets. After 10 days, the total organic N release from SPC-BP becomes significantly higher, compared to the neat SPC. At day 25, the cumulative organic $\mathrm{N}$ release from SPC-BP approaches the value for the pellets containing urea. It seems, therefore, that BP allows a better more gradual organic N release from the SPC pellets. This may happen due to interaction of the two biopolymers yielding a product with different solubility properties than the pristine SPC and BP. 


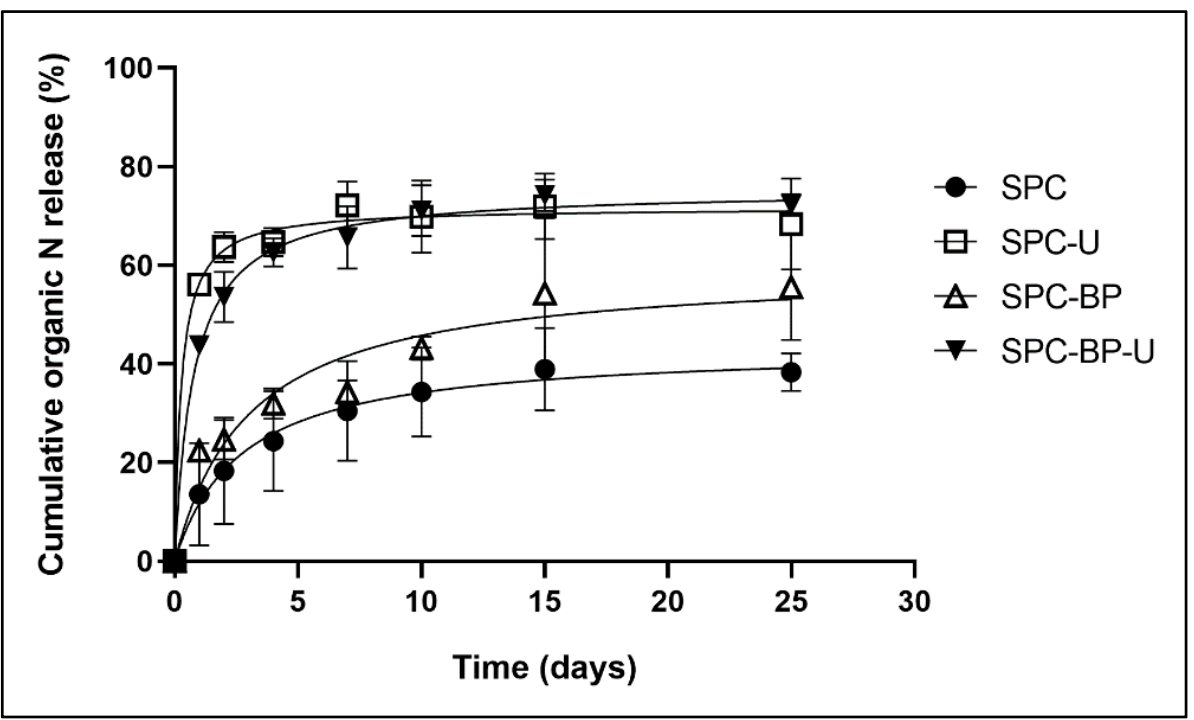

Figure 11. Percentage of initial $\mathrm{N}$ released in solution as total organic N.

\subsection{Evaluation of the Total $\mathrm{C}$ and Nutrients' Release}

At the end of the experiment, the solid residues of the samples were dried, weighed, and analyzed for the C, N, P, and K content. The comparison between the initial (Table 1) and final amounts of these elements, allows calculating the percentage of release of each one. The results are reported in Table 8 . The loss of weight was about $70 \%$ in 25 days, without significant differences between the samples. The nutrient release results were affected by a high variability because they were derived from the elaboration of several parameters (weight, initial and final nutrient contents), therefore subject to the error propagation laws. The $\mathrm{N}$ release reflected the results obtained by direct analysis of the solution (Figure 9), but no significant difference between the samples could be pointed out for the reason explained above. The average $C$ and $P$ release were, respectively, $64.7 \%$ and $73.2 \%$, more or less reflecting the loss of weight. In contrast, nearly all the initial K (>97\%) was solubilized.

Table 8. Percentage of release in solution of total $C$ and nutrients after 25 days experiment, and pellets mass decrease, relative to the initial values in the formulation ${ }^{1}$.

\begin{tabular}{cccccc}
\hline Formulation & $\begin{array}{c}\text { Mass } \\
\text { Decrease }\end{array}$ & C Release & N Release & P Release & K Release \\
\hline SPC & $69.7 \pm 5.0^{\mathrm{a}}$ & $63.3 \pm 5.7^{\mathrm{a}}$ & $59.9 \pm 10.0^{\mathrm{a}}$ & $70.0 \pm 6.8^{\mathrm{a}}$ & $98.3 \pm 0.1^{\mathrm{a}}$ \\
SPC-U & $71.9 \pm 1.0^{\mathrm{a}}$ & $63.5 \pm 1.5^{\mathrm{a}}$ & $72.7 \pm 2.1^{\mathrm{a}}$ & $78.2 \pm 21.2^{\mathrm{a}}$ & $98.6 \pm 1.2^{\mathrm{a}}$ \\
SPC-BP & $72.8 \pm 8.8^{\mathrm{a}}$ & $67.7 \pm 10.3^{\mathrm{a}}$ & $68.7 \pm 15.7^{\mathrm{a}}$ & $66.7 \pm 19.6^{\mathrm{a}}$ & $97.8 \pm 1.3^{\mathrm{a}}$ \\
SPC-BP-U & $71.6 \pm 7.1^{\mathrm{a}}$ & $64.2 \pm 8.3^{\mathrm{a}}$ & $71.8 \pm 11.9^{\mathrm{a}}$ & $77.9 \pm 5.8^{\mathrm{a}}$ & $99.0 \pm 0.2^{\mathrm{a}}$ \\
\hline
\end{tabular}

${ }^{1}$ As all values in the same column are always followed by the same letter (a), they are not significantly different $(p<0.05)$.

\section{Discussion}

\subsection{Manufacture of the Pellets Through Twin-Screw Extrusion}

In this study, in addition to the pellets produced using the twin-screw extrusion technology, it has also been envisaged to convert them into injection-molded pieces. Because it is carried out under pressure, the injection-molding technique allowed producing pieces that were much denser than the pellets from which they were obtained (Table 2). The higher density of the injected pieces was indicative of largely reduced internal porosity. Thanks to their densification, the injected pieces were much more mechanically resistant than the extruded pellets they came from. This was evidenced by their quite promising tensile (Table 4) and bending (Table 5) properties, as well as their high Shore D surface hardness (Table 6). The injection-molded pieces were also much more resistant to mechanical abrasion than the 
pellets (Table 3), enabling them to be suitable for their intended use, i.e., their spreading to the field, with the assurance that very few fines will be generated during this mechanized operation. This could be a real advantage for high-throughput applications. In parallel, because of their lower internal porosity, it is reasonable to assume that injection-molded pieces would be more resistant to water than the pellets, thus reducing the kinetics of urea release over time. The water immersion tests carried out on the injection-molded pieces nevertheless showed that the longer they were soaked in water, the more water they absorbed (Figure 6). The same trend was also evidenced in terms of thickness swelling (Figure 5).

In more detail, when looking at the results of resistance to mechanical abrasion, it should be acknowledged that when fines (\%) are increasing, the material is less resistant to mechanical abrasion. The results in Table 3 show that the injected pieces are all really resistant to mechanical abrasion as the fines generated during the test are always very low (i.e., $0,7 \%(w / w)$ max). This can be explained by the densification of the injected pieces compared with the extruded pellets. However, when comparing the values obtained for the four injected formulations, there is no significant difference in terms of resistance to mechanical abrasion between SPC, SPC-U, SPC-BP, and SPC-BP-U. Indeed, the amount of fines generated ranged from $0.4 \%$ to $0.7 \%(w / w)$, and this was expected as all the injected formulations have quite the same density values $\left(1362-1398 \mathrm{~kg} / \mathrm{m}^{3}\right)$.

On the opposite, compared with the injected pieces, the resistance to mechanical abrasion of the extruded pellets is really bad. Fines range from $11.5 \%$ to $68.8 \%(w / w)$. This is due to the much higher internal porosity as related to the lower density values $\left(783-1122 \mathrm{~kg} / \mathrm{m}^{3}\right)$. The result is that the extruded pellets are more friable. Based on the fines generated, the extruded pellets rank in the following order of decreasing resistance to mechanical abrasion: SPC-U (11.5\% fines) > SPC-BP-U (32.5\% fines) > SPC-BP ( $55.9 \%$ fines) $>$ SPC $(68.8 \%$ fines). This is in line with the decreasing pellet density values. A second reason may be the unexpected important plasticizing effect of urea on proteins that will be discussed later, which gives to the SPC-U extruded pellets a better elasticity. Thus, they are better supporting deformation at impact, and fines generation from the SPC-U extruded pellets is unfavored. This same remark applies when comparing SPC-BP-U, SPC-BP, and SPC but in a lesser extent. In essence, BP exhibit a reduced plasticizing effect on SPC proteins, compared with urea. This is in perfect accordance with the tensile and bending results conducted from the injected pieces: The less the elastic modules, the more the plasticizing effect.

Differences in mechanical strength were also found by other authors investigating urea granules coated with $20 \%$ mix made of polyvinyl alcohol and other natural biodegradable polymers [36]. They reported $140 \%$ higher crushing strength for urea granules coated with $10 \%$ starch $-5 \%$ polyvinyl alcohol mix, compared with uncoated urea granules, and $10 \%$ higher crushing strength, compared with urea granules coated with other biodegradable polymers such as molasses, gelatin, gum Arabic, and paraffin wax. The as defined "crushing strength" is in fact more comparable to the resistance to mechanical abrasion presented in this study, as it was used by the authors to estimate the tendency of granules to turn into fine powder. The results reported for the SPC-based composites in the present work show that all the injection-molded pieces are fully abrasion-resistant as fines generated are always negligible (Table 3). The differences in mechanical behavior between the SPC-based composite pellets obtained in the present work by extrusion (Table 3 ) and between the coated urea granules reported by other workers [36], as compared to the high resistance and no differences shown by the injection-molded SPC-based composites, evidences the great advantage of the injection-molding process. When conducted, it results in high densification, surface hardening, and negligible fines generation during the resistance to mechanical abrasion test. In fact, the injection-molding step levels out the differences in resistance to mechanical abrasion due to the different formulations of the SPC-based materials. 
The surface hardness values of the injected pieces show a different order: SPC-BP > SPC-BP-U > SPC > SPC-U. It is evident that BP contributes more than urea to the hardening of the composite surface. The more BP is added, the higher the surface hardness.

Regarding the plasticizing effect of urea on proteins mentioned just above, it could be explained by the low steric dimension (i.e., low molecular weight) of the urea molecule on the one hand, and by its affinity of chemical structure with proteins on the other hand. As a reminder, proteins are co-polymers of amino acids linked together by peptide bonds, the latter being in the form of a CO-NH (i.e., type amide) function. This same functional group is also present in the urea molecule. Urea can thus easily position itself between the protein chains within the SPC matrix, leading to their plasticization. This plasticizing effect was confirmed thanks to the tensile tests conducted on the injection-molded pieces (Table 4 and Figure 3), as the presence of $U$ inside the formulation resulted in a large decrease in the elastic modulus, simultaneously with a large increase in both elongations at maximal strength and at break. At the same time, maximal tensile strength and tensile strength at rupture were slightly reduced. All these observations are in perfect accordance with a plasticizing effect. The same observations were also made during the bending tests (Table 5 and Figure 4), with nevertheless a decrease in the flexural strengths at break in a greater proportion. In the same way, a plasticizing effect was also evidenced for BP and for the BP/U mixture at the 50/50 (w/w) proportion. However, it was less significant. As a result, the extruded pellets and especially the injection-molded pieces have more ductility when mixed with $\mathrm{U}, \mathrm{BP}$, or BP-U. These related materials thus become more flexible (i.e., less brittle), consistently with the decrease in the elastic modules.

\subsection{The Pellets' Properties}

$\mathrm{BP}$ does not have film forming properties. The chemical memory of the pristine lignocellulosic structure does not allow fabricating flexible films with adequate properties for use in the manufacture of plastic articles. However, in the case of the composite pellets of the present work, the mechanical strength of their lignocellulosic structural memory contributes the advantage of increasing the mechanical resistance of the composite pellets. Table 6 shows that the two SPC-BP and SPC-BP-U injection-molded pieces, respectively, exhibit 56\% and 32\% higher Shore D surface hardness than that of the SPC-U injectionmolded pieces, which in turn is even lower than that of the SPC ones. The data indicate clearly that urea lowers the surface hardness of the neat SPC. On the contrary, BP not only increases the surface hardness of the neat SPC pieces, but also compensates the negative effect of urea. This specific property of BP is not new. Biagini and coworkers [39] fabricated and measured the mechanical resistance of animal feed pellets containing proteins and fibers, to which 5-10\% BP was added. They found that, compared to the control pellets (no added BP), the pellets containing BP exhibited 18-20\% higher resistance to shear and compression. Other authors reported an increase in the crushing strength of $59 \%$ for urea coated with $20 \%$ pine lignin [13].

Mechanical strength is not the only benefit contributed by BP. This biopolymer is also shown to inhibit the hydrolysis of urea and formation of ammonia. Thus, a further environmental benefit is expected from BP, i.e., lowering ammonia and derived $\mathrm{N}_{2} \mathrm{O}$ gas emission and/or decreasing ammonia and derived nitrates leaching through soil into ground water. Because of the rapid hydrolysis of urea occurring in the release trials performed in the present work (Figure 8), urea is an unsuitable indicator of the behavior of the SPC-based composite materials as CRFs. Ammonia, as product of urea hydrolysis, is an indirect indicator of the urea release rate (Figure 9). However, all investigated SPC-based materials contain organic $\mathrm{N}$, which can be hydrolyzed to ammonia. Moreover, all three components of the SPC-based composites have fertilizer power. Under these circumstances, total $\mathrm{N}$ appears the best indicator of the SPC composites' performance as CRFs.

Table 9 reports the results from the interpolation of Figure 10 data with Equation (1).

$$
N_{\mathrm{t}}=N_{\mathrm{e}} \times t /(K \mathrm{~d}+t)
$$


where $N_{\mathrm{t}}$ is the total nitrogen released at time $t$, expressed as $\%$ of the total nitrogen in the material at time $0, N_{\mathrm{e}}$ is the maximum total nitrogen released, expressed as \% of the total nitrogen in the material at time 0 , extrapolated to very high solid-water contact time upon reaching equilibrium, and $\mathrm{Kd}$ is the time $\mathrm{t}$ needed to reach $50 \% \mathrm{~N}_{\mathrm{e}}$. The first derivative of Equation (1) yields Equation (2).

$$
\mathrm{d} N_{\mathrm{t}} / \mathrm{d} t=N_{\mathrm{e}} \times\left[(K \mathrm{~d}+2 t) /(K \mathrm{~d}+t)^{2}\right]
$$

which describes the decrease of the total nitrogen release rate upon increasing the contact time between the solid and water.

Table 9. Results from the interpolation of Figure 10 data with Equation (1): Constants $\left(N_{\mathrm{e}}\right.$ and $\left.K \mathrm{~d}\right)$, and correlation coefficient $(R)$.

\begin{tabular}{ccccc}
\hline Formulation & SPC & SPC-U & SPC-BP & SPC-BP-U \\
\hline $\begin{array}{c}\text { Total N in pellet at time } \\
0(\%, w / w)\end{array}$ & 6.9 & 10.5 & 7.0 & 8.5 \\
$N_{\mathrm{e}}$ & 56.4 & 80.4 & 69.7 & 83.8 \\
$K \mathrm{~d}$ & 4.100 & 0.392 & 3.660 & 0.915 \\
$R$ & 0.913 & 0.983 & 0.953 & 0.990 \\
Total $N$ in pellet at & 3.01 & 2.06 & 2.12 & 1.38 \\
equilibrium $(\%, w / w)$ & & & & \\
\hline
\end{tabular}

The $\mathrm{N}_{\mathrm{e}}$ values in Table 9 reflect the mass and nutrients decrease data in Table 8 . This allows calculating the residual total nitrogen in the pellet at equilibrium. The $\mathrm{Kd}$ values evidence the different release rates of the pellets. The order of decreasing rate is SPC-U > SPC-BP-U > SPC-BP > SPC. The same is also evidenced in the plots of Equation (2) (Figure 12). It is clear that urea is the fastest component to be released, and SPC is the slowest one. BP allows modulating the nitrogen release of the other two components. For instance, BP in the SPC-BP-U pellet allows slowing down the release rate of urea, whereas BP in the SPC-BP one accelerates the release rate of SPC nitrogen. In fact, the four different formulations represent a range of materials with different nutrient release rates.

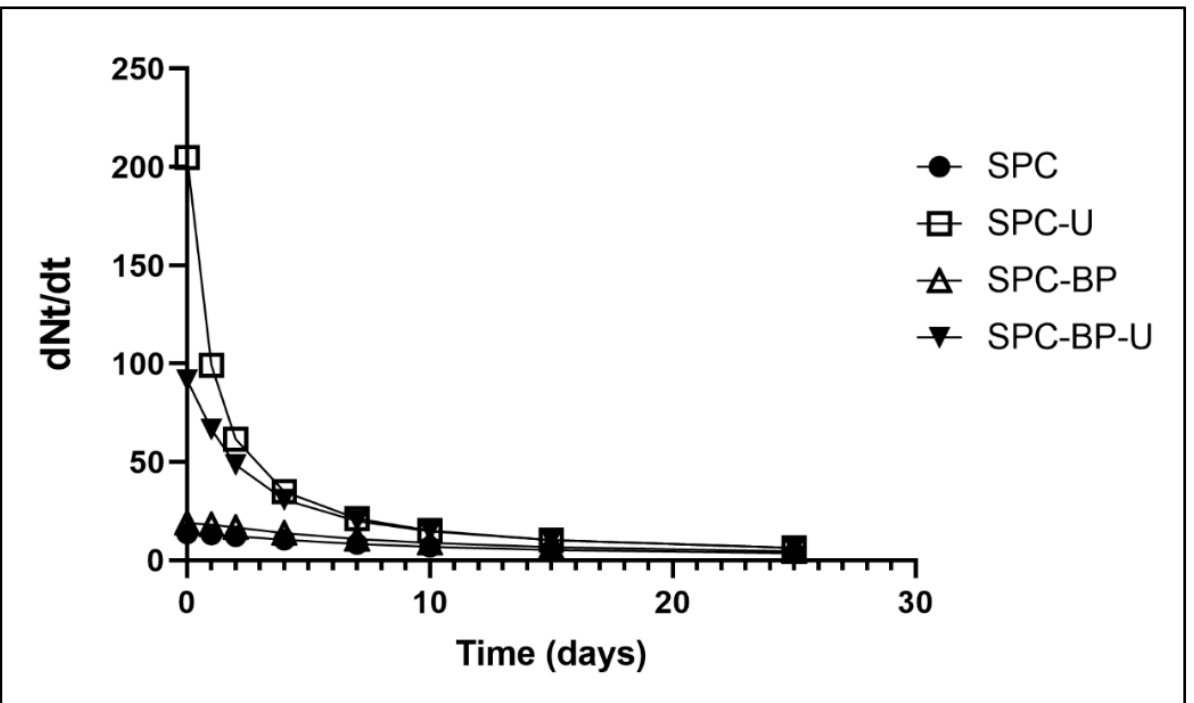

Figure 12. Change of total nitrogen release rate upon increasing the SPC-based composite pelletswater contact time. 
The BP biopolymer is a multifunctional product. It contains several acid, basic, and chelating functional groups [9]. The BP effect to control the release of urea and organic nitrogen from the composite pellets is likely to be due to the interaction of its functional groups with urea and SPC. The BP is also a proven soil fertilizer and plant growth biostimulants [9]. All of the above BP properties may work synergically with the properties of urea and SPC, making SPC-BP-U a powerful eco-friendly CRF containing, and capable of releasing and providing soil and plants, organic $\mathrm{C}$ and the three major $\mathrm{N}$, $\mathrm{P}, \mathrm{K}$ nutrients (Table 8). The combination of the three components in different relative ratios may allow tailoring the release rate to the specific requirements in real agriculture practices for specific cultivations. This perspective offers scope for worthwhile testing the performance of the SPC-BP-U pellets in specific plants' cultivation trials.

\section{Conclusions}

An efficient process has been developed to manufacture a new composite biomaterial made from the two SPC and BP biopolymers, and urea. The composite material has been fabricated in the forms of extruded pellets and then injection-molded pieces, although it contains components having no film forming properties or not processable through extrusion. First of all, the twin-screw extrusion process comprises two main phases, carried out continuously in the extruder depicted in Figure 1. First, SPC is destructured and rendered thermo-plastic by adding aqueous sodium sulfite. In the second phase, BP and urea are added into the thermoplastic SPC matrix and homogeneized under pressure as the blend proceeds to the exit of the extruder. Additionally, the extruded pellets generated can be transformed into denser pieces through injection-molding.

The injection-molded composites, in the form of dense pellets and characterized for their mechanical and nitrogen release properties, have evidenced a number of specific benefits contributed by BP. These allow for concluding that the manufacture process and the formulation of the composite make possible producing new biomaterials in the form of dense pellets from the renewable SPC and BP biopolymers, and urea. These have all mechanical and nutrient release properties for being tested as eco-friendly CRFs for the cultivation of specific plants.

Supplementary Materials: The following are available online at https:/ /www.mdpi.com/2079-6 $412 / 11 / 1 / 43 / s 1$, Table S1: Calculated amount of $\mathrm{N}$ from each component $\left(\mathrm{N}_{\mathrm{SPC}}, \mathrm{N}_{\mathrm{BP}}, \mathrm{N}_{\mathrm{U}}\right)$ in the blended SPC-U, SPC-BP, SPC-BP-U pellets compared to the total N amount released in solution from the pellets. Calculations based on the $4 \mathrm{~g}$ sample weight (see Materials and Methods), on the composite formulations, and on Table 1 data.

Author Contributions: C.V.-G. and E.M. developed the concept, acquired the funds for the work dedicated to the manufacture of the composite pellets and the characterization of their properties, and supervised it. P.E., L.L., and C.V.-G. developed the process, manufactured, and characterized the mechanical properties of the composite pellets. E.P., V.B., and M.N. performed the characterization, and developed the analytical procedure for the release properties of the composite pellets. E.M. developed the process to manufacture BP, and its analytical protocol. E.M. wrote the original draft of the paper. P.E. edited the final version of the paper. C.V.-G. and M.N. administered the funds at their institution, respectively, to carry out the work. All authors reviewed and completed the paper before submission and agreed to the published version of the manuscript.

Funding: This research was supported partly by endowed funds of the authors' institutions, and partly funded by the European Commission in order to support the implementation of the actions pursued in the LIFE16 ENV/IT/000179-LIFECAB and the LIFE19 ENV/IT/000004-LIFEEBP projects.

Data Availability Statement: Data is contained within the article or supplementary material.

Acknowledgments: The authors acknowledge the kind assistance of Claudio Spitaleri (Istituto Nazionale di Fisica Nucleare, LNS, Catania, Italy) for the mathematical elaboration of the kinetics data.

Conflicts of Interest: The authors declare no conflict of interest. 


\section{References}

1. Trenkel, M.E. Slow- and Controlled-Release and Stabilized Fertilizers: An Option for Enhancing Nutrient Use Efficiency in Agriculture; International Fertilizer Industry Association (IFA): Paris, France, 2010; Available online: www.fertilizer.org (accessed on 4 December 2020).

2. Ramli, R.A. Slow release fertiliser hydrogels: A review. Polymer 2019, 10, 6073-6090.

3. Razza, F.; Briani, C.; Breton, T.; Marazza, D. Metrics for quantifying the circularity of bioplastics: The case of bio-based and biodegradable mulch films. Resour. Conserv. Recycl. 2020, 159, 104753. [CrossRef]

4. Majeed, Z.; Ramli, N.K.; Mansor, N.; Man, Z. A comprehensive review on biodegradable polymers and their blends used in controlled-release fertilizer processes. Rev. Chem. Eng. 2015, 31, 69-95. [CrossRef]

5. Bio Technologies LLC. Sunprotein 2018. Available online: http://www.biot.pro/eng/products/food/sunprotein (accessed on 4 December 2020).

6. Salgado, P.R.; Ortiz, S.E.M.; Petruccelli, S.; Mauri, A.N. Functional food ingredients based on sunflower protein concentrates naturally enriched with antioxidant phenolic compounds. J. Am. Oil Chem. Soc. 2012, 89, 825-836. [CrossRef]

7. Salgado, P.R.; López-Caballero, M.E.; Gómez-Guillén, C.; Mauri, A.N.; Montero, M.P. Exploration of the antioxidant and antimicrobial capacity of two sunflower protein concentrate films with naturally present phenolic compounds. Food Hydrocoll. 2012, 29, 374-381. [CrossRef]

8. Rouilly, A.; Mériaux, A.; Geneau, C.; Silvestre, F.; Rigal, L. Film extrusion of sunflower protein isolate. Polym. Eng. Sci. 2006, 46, 1635-1640. [CrossRef]

9. Montoneri, E. Municipal waste treatment, technological scale up and commercial exploitation: The case of bio-waste lignin to soluble lignin-like polymers. In Food Waste Reduction and Valorisation; Morone, P., Papendiek, F., Tartiu, V.E., Eds.; Springer: Berlin/Heidelberg, Germany, 2017; Chapter 6. [CrossRef]

10. Nisticò, R.; Evon, P.; Labonne, L.; Vaca-Medina, G.; Montoneri, E.; Francavilla, M.; Vaca-Garcia, C.; Magnacca, G.; Franzoso, F.; Negre, M. Extruded poly(ethylene-co-vinyl alcohol) composite films containing biopolymers isolated from municipal biowaste. Chem. Sel. 2016, 1, 2354-2365. [CrossRef]

11. Franzoso, F.; Causone, D.; Tabasso, S.; Antonioli, D.; Montoneri, E.; Persico, P.; Laus, M.; Mendichi, R.; Negre, M. Films made from polyethylene-co-acrylic acid and soluble biopolymers sourced from agricultural and municipal biowaste. J. Appl. Polym. Sci. 2015, 132, 5803. [CrossRef]

12. IFA. Consumption Urea World 2017. Available online: https://www.ifastat.org/databases/plant-nutrition (accessed on 4 December 2020).

13. Garcia, M.C.; Daez, J.A.; Vallejo, A.; Garcia, L.; Cartagena, M.C. Use of kraft pine lignin in controlled-release fertilizer formulations. Ind. Eng. Chem. Res. 1996, 35, 245-249. [CrossRef]

14. Mulder, W.J.; Gosselink, R.J.A.; Vingerhoeds, M.H.; Harmsen, P.F.H.; Eastham, D. Lignin based controlled release coatings. Ind. Crops Prod. 2011, 34, 915-920. [CrossRef]

15. Fernández-Pérez, M.; Garrido-Herrera, F.J.; González-Pradas, E.; Villafranca-Sánchez, M.; Flores-Céspedes, F. Lignin and ethylcellulose as polymers in controlled release formulations of urea. J. Appl. Polym. Sci. 2008, 108, 3796-3803. [CrossRef]

16. Ariyanti, S.; Man, Z.; Azmi, B.M. Improvement of hydrophobicity of urea modified tapioca starch film with lignin for slow release fertilizer. Adv. Mater. Res. 2012, 626, 350-354. [CrossRef]

17. ISO. ISO 5983-1:2005, Animal Feeding Stuffs-Determination of Nitrogen Content and Calculation of Crude Protein Content-Part 1: Kjeldahl Method; International Organization for Standardization: Geneva, Switzerland, 2005.

18. ISO. ISO 749:1977, Oilseed Residues-Determination of Total Ash; International Organization for Standardization: Geneva, Switzerland, 1977.

19. ISO. ISO 659:2009, Oilseeds-Determination of Oil Content; International Organization for Standardization: Geneva, Switzerland, 2009.

20. Van Soest, P.J.; Wine, R.H. Use of detergents in the analysis of fibrous feeds. Part IV. Determination of plant cell-wall constituents. J. Assoc. Off. Agric. Chem. 1967, 50, 50-55.

21. Van Soest, P.J.; Wine, R.H. Determination of lignin and cellulose in acid-detergent fiber with permanganate. J. Assoc. Off. Agric. Chem. 1968, 51, 780-785. [CrossRef]

22. Rigal, L.; Silvestre, F.; Doumeng, C.; Leyris, J.; Gaset, A. Method For Making Shaped Objects from a Vegetable Raw Material by Injection-Moulding. European Patent EP0988948, 29 March 2000.

23. Humbert, J.; Makoumbou, U.; Rigal, L.; Chelle, R.; Rouilly, A.; Geneau Sbartai, C. Matériau Plastique Composite Sous la Forme de Granulats Issus de Matières Protéiques Végétales et son Procédé de Fabrication. French Patent FR2940297, 25 June 2010.

24. ISO. ISO 527-4:1997, Plastics-Determination of Tensile Properties-Part 4: Test Conditions for Isotropic and Orthotropic Fibre-Reinforced Plastic Composites; International Organization for Standardization: Geneva, Switzerland, 1997.

25. ISO. ISO 178:2010, Plastics-Determination of Flexural Properties; International Organization for Standardization: Geneva, Switzerland, 2010.

26. ISO. ISO 868:2003, Plastics and Ebonite-Determination of Indentation Hardness by Means of a Durometer (Shore Hardness); International Organization for Standardization: Geneva, Switzerland, 2003.

27. ISO. ISO 16983:2003, Wood-Based Panels-Determination of Swelling in Thickness after Immersion in Water; International Organization for Standardization: Geneva, Switzerland, 2003. 
28. Chen, L.; Ma, J.; Huang, Y.; Dai, M.; Li, X. Optimization of a colorimetric method to determine trace urea in sea water. Limnol. Oceanogr. Methods 2015, 13, 303-311. [CrossRef]

29. Geneau-Sbartaï, C. Manufacturing Process of Agromaterial Natural Composite by Twin-Screw Extrusion and Injection Moulding from Sunflower Cake. Ph.D. Thesis, INP, Toulouse, France, 2006.

30. Silvestre, F.; Rigal, L.; Leyris, J.; Gaset, A. Aqueous Adhesive Based on a Vegetable Protein Extract and Process for the Preparation. French Patent FR2785288, 5 May 2000.

31. Ordonez, C.; Tejada, M.; Benitez, C.; Gonzalez, J.L. Characterization of a phosphorus-potassium solution obtained during a protein concentrate process from sunflower flour. Application on rye-grass. Bioresour. Technol. 2006, 97, 522-528. [CrossRef]

32. Ordonez, C.; Benitez, C.; Gonzalez, J.L. Amino acid production from a sunflower wholemeal protein concentrate. Bioresour. Technol. 2008, 99, 4749-4754. [CrossRef]

33. Ugolini, L.; Cintia, S.; Righetti, L.; Stefan, A.; Matteo, R.; D’Avino, L.; Lazzeria, L. Production of an enzymatic protein hydrolyzate from defattedsunflower seed meal for potential application as a plant biostimulant. Ind. Crops Prod. 2015, 75, 15-23. [CrossRef]

34. Evon, P.; Vandenbossche, V.; Candy, L.; Pontalier, P.Y.; Rouilly, A. Twin-screw extrusion: A key technology for the biorefinery. In Biomass Extrusion and Reaction Technologies: Principles to Practices and Future Potential; American Chemical Society, ACS Symposium Series, eBooks; American Chemical Society: Washington, DC, USA, 2018; Volume 1304, pp. 25-44.

35. Sigurdarson, J.J.; Svane, S.; Karring, H. The molecular processes of urea hydrolysis in relation to ammonia emissions from agriculture. Rev. Environ. Sci. Biotechnol. 2018, 17, 241-258. [CrossRef]

36. Beig, B.; Niazi, M.B.K.; Jahan, Z.; Kakar, S.J.; Shah, G.A.; Shahi, M.; Zia, M.; Haq, M.U.; Rashid, M.I. Biodegradable polymer coated granular urea slows down N release kinetics and improves spinach productivity. Polymers 2020, 12, 2623. [CrossRef]

37. Biagini, D.; Montoneri, E.; Rosato, R.; Lazzaroni, C.; Dinuccio, E. Reducing ammonia and GHG emissions from rabbit rearing through a feed additive produced from green urban residues. Sustain. Prod. Consum. 2021, 27, 1-9. [CrossRef]

38. Khalid, N.N.A.; Ashaari, Z.; Mohd, A.H.; Mohamed, H.A.; Lee, S.H. Nitrogen deposition and release pattern of slow release fertiliser made from urea-impregnated oil palm frond and rubberwood chips. J. For. Res. 2019, 30, 208762094. [CrossRef]

39. Biagini, D.; Gasco, L.; Rosato, R.; Peiretti, P.G.; Gai, F.; Lazzaroni, C.; Montoneri, C.; Ginepro, M. Compost-sourced substances (SBO) as feedstuff additives in rabbit production. Anim. Feed Sci. Technol. 2016, 214, 66-76. [CrossRef] 